\title{
Spatio-Temporal Patterns of Drought and Impact on Vegetation in North and West Africa Based on Multi-Satellite Data
}

\author{
Malak Henchiri ${ }^{1,2}$, Qi Liu ${ }^{3}$, Bouajila Essifi ${ }^{4}{ }^{\oplus}$, Tehseen Javed ${ }^{1,2}{ }^{-0}$, Sha Zhang ${ }^{1,2}$, Yun Bai ${ }^{1,2}$ \\ and Jiahua Zhang $2,3,5, *$ (D) \\ 1 School of Automation, Qingdao University, Qingdao 266071, China; 2017520009@qdu.edu.cn (M.H.); \\ tehseenjaved@nwafu.edu.cn (T.J.); zhangsha@qdu.edu.cn (S.Z.); baiyun@qdu.edu.cn (Y.B.) \\ 2 Remote Sensing Information and Digital Earth Center, School of Computer Science and Technology, \\ Qingdao University, Qingdao 266071, China \\ 3 College of Earth and Planetary Sciences, University of Chinese Academy of Sciences, Beijing 100049, China; \\ liuqi203@mails.ucas.ac.cn \\ 4 Laboratory of Eremology and Combating Desertification, Institut des Regions Arides (IRA), \\ Medenine 4119, Tunisia; Bouajila.Essifi@ira.agrinet.tn \\ 5 Key Laboratory of Digital Earth Science, Aerospace Information Research Institute, \\ Chinese Academy of 'Sciences, Beijing 100094, China \\ * Correspondence: zhangjh@radi.ac.cn; Tel.: +86-1368-357-6879
}

Received: 14 October 2020; Accepted: 23 November 2020; Published: 25 November 2020

\begin{abstract}
Studying the significant impacts of drought on vegetation is crucial to understand its dynamics and interrelationships with precipitation, soil moisture, and temperature. In North and West Africa regions, the effects of drought on vegetation have not been clearly stated. Therefore, the present study aims to bring out the drought fluctuations within various types of Land Cover (LC) (Grasslands, Croplands, Savannas, and Forest) in North and West Africa regions. The drought characteristics were evaluated by analyzing the monthly Self-Calibrating Palmer Drought Severity Index (scPDSI) in different timescale from 2002 to 2018. Then, the frequency of droughts was examined over the same period. The results have revealed two groups of years (dry years and normal years), based on drought intensity. The selected years were used to compare the shifting between vegetation and desert. The Vegetation Condition Index (VCI), the Temperature Condition Index (TCI), the Precipitation Condition Index (PCI), and the Soil Moisture Condition Index (SMCI) were also used to investigate the spatiotemporal variation of drought and to determine which LC class was more vulnerable to drought risk. Our results revealed that Grasslands and Croplands in the West region, and Grasslands, Croplands, and Savannas in the North region are more sensitive to drought. A higher correlation was observed among the Normalized Difference Vegetation Index (NDVI), Land Surface Temperature (LST), Tropical Rainfall Measuring Mission (TRMM), and Soil Moisture (SM). Our findings suggested that NDVI, TRMM, and SM are more suitable for monitoring drought over the study area and have a reliable accuracy $\left(R^{2}>0.70\right)$ concerning drought prediction. The outcomes of the current research could, explicitly, contribute progressively towards improving specific drought mitigation strategies and disaster risk reduction at regional and national levels.
\end{abstract}

Keywords: Drought Indices; North and West Africa; shifting; Spatiotemporal Variations; Vegetation Response 


\section{Introduction}

Drought is one of the most severe natural disasters throughout the world [1-4]. That is defined as an extended period with abnormal low rainfall relative to the statistical multi-year average, which causes changes in vegetation [5,6]. However, the American Meteorological Society (AMS) classifies it into four major types: meteorological drought results from lack of rain in an area during a selected period. Hydrological drought is associated with a lack of surface and underground water, while agricultural drought refers to a deficiency in water accessibility for plant growth. Finally, socio-economic drought is related to insufficient supply to meet the demand of various economic goods with the above three types of drought [7-9]. According to the Intergovernmental Panel on Climate Change (IPCC), drought is set to increase globally in both frequency and severity due to climate change [10]. The climate of the African continent exhibits large spatiotemporal variability [11]. In the study region, Northern Africa receives low rainfall mostly from October until April [12-14], while in West Africa, the maximum precipitation occurred from July to September, and August being the wettest month [15]. In Africa, there were frequent drought events that occurred in the last decades [16]. Touchan et al. [17] studied the long-term perspective on droughts in northwestern Africa. They reported that the 20th century emerged as the driest among the last nine centuries. The most severe multi-year drought occurred during 1999-2002, whereas 1847 and 2002 were identified as the driest single years with the Palmer Drought Severity Index (PDSI) values of -3.74 and -3.90 , respectively [17]. Furthermore, Shiferaw et al. [18] and Bhavani et al. [19] reported that droughts cause nearly $80 \%$ of the loss of life and $70 \%$ of the economic losses in Sub Saharan Africa. Frequently drought events have troubled the economic development of several African countries [20] and endangered their developmental gains [21,22].

Numerous drought indices can efficiently monitor droughts, such as the Palmer Drought Severity Index (PDSI) [23], the Standardized Precipitation Index (SPI) [4,24], and the Standardized Precipitation Evapotranspiration Index (SPEI) $[25,26]$. The PDSI was introduced in 1965 and has been continuously improved by numerous researchers [23]. PDSI has great success in quantifying the severity of long-term drought, but it was unsatisfactory for assessing short-term drought and inconsistent comparisons between different climatological regions [27]. The self-calibrating PDSI (scPDSI) presented by Wells et al. [28] significantly improved PDSI spatial comparability and made it more suitable for monitoring extreme dry and wet events. Therefore, monitoring the drought at one-, three-, six-, nineand 12-month timescale is very useful for analyzing vegetation's response to drought, making PDSI less reasonable for drought monitoring [27]. For that, a systematic analysis of the scPDSI with a 1-12 month timescale was made. However, as a regional event, drought needs to be monitored not only on a time scale but also over space [29]. Remote sensing datasets can continuously and systematically offer information such as water cycles and vegetation. Thus, remotely sensed drought indices could be used for spatiotemporal drought monitoring [30,31].

Remote sensing is a significant approach for monitoring drought due to its practical benefits in different weathers [32]. It gives various variables closely related to numerous climatic parameters, such as the land surface temperature (LST), the precipitation derived from the Tropical Rainfall Measuring Mission (TRMM), and the soil moisture (SM) [33,34]. The Normalized Difference Vegetation Index (NDVI) has been used extensively for vegetation monitoring and drought assessment [35-37]. To further monitor drought and vegetation status, Kogan et al. [38] developed the Vegetation Condition Index (VCI), the precipitation condition index (PCI), the temperature condition index (TCI) and the soil moisture condition index (SMCI) [38].

However, less attention has been paid to the temporal study and spatial patterns of drought monitoring over the study region. The gap in knowledge due to limited empirical studies on droughts and its impact on vegetation over the region may hamper our understanding the impacts of varying climate on the ecosystems $[13,15]$. Agriculture is the most vulnerable sector impacted by drought [39-43]. Therefore, monitoring drought hazard and its impact is critical due to the widespread effects of drought on various agro-ecological systems [44,45]. Some studies [43] suggested that VCI is more accurate index for vegetation drought assessment, while several other studies $[37,41,42,46,47]$ 
suggested PCI and TCI are the standard methods for vegetation drought monitoring. In this study, scPDSI at different timescale with PCI, TCI, VCI and SMCI were selected to monitor the impact of drought on vegetation.

The main objectives of this study are:

(1) To evaluate the efficiency of scPDSI at one-, three-, six-, nine-, and 12-month timescales for drought monitoring in (NW) regions of the study area from 2002 to 2018.

(2) To evaluate the spatiotemporal patterns of seasonal PCI, TCI, VCI, and SMCI indices, and to compare the shifting between vegetation and desert during four dry years and two normal years.

(3) To monitor the impact of drought on local vegetation and determine which vegetation cover type is most vulnerable to drought risk.

\section{Materials and Methods}

\subsection{Study Area}

The study region covers the North and West of Africa regions. This area lies between longitudes $18^{\circ} \mathrm{W}$ and $40^{\circ} \mathrm{E}$ and latitudes $4^{\circ}$ and $38^{\circ} \mathrm{N}$, it is encompassed by the Mediterranean Sea in the North, the Atlantic Ocean in the West and Southwest, East and Central Africa in the Southeast and the Red Sea in the East (Figure 1) [48]. The climate of the study regions exhibits large spatiotemporal variability [11]. The rainy season in the North region starts from October until April with a deficient rainfall [12-14]. In the west region, the rainy season starts from July until September, with August the wettest month [15]. Therefore in this work, we divided the study area into two-part North region and West region to better analyze the spatiotemporal pattern of drought and its impact on vegetation.



Figure 1. Study area.

The monthly precipitation and temperature datasets from 2002 to 2018 used in this work are the Climate Research (CRU) data developed by the University of East Anglia at $0.5^{\circ} \times 0.5^{\circ}$ spatial resolution (http://data.ceda.ac.uk/badc/cru/data/cru_ts/cru_ts_4.04/data). These datasets were used to calculate scPDSI at one-, three-, six-, nine-, and 12-month timescales [49,50]. Two MODIS products used in this study, firstly the NDVI (MOD13A1, v006) at $500 \mathrm{~m}$ spatial resolution from 2002 to 2018 
were obtained from the National Aeronautics and Space Administration Earth Observing System Data and Information System (NASA-EOSDIS) (http://disc.sci.gsfc.nasa.gov/). We used the TIMESAT software package for cleaning the MOD13A1 dataset. We have selected a median filtration to remove outliers for suppressing disturbances and the dual logistic method for smoothing the datasets [51]. The cleaned and smoothed MOD13A1 were resampled to $1 \mathrm{~km}$ and used to calculate VCI values [38]. Secondly, the MODIS LST (MOD11A2, collection v006) 8-day from 2002 to 2018 at $1 \mathrm{~km}$ spatial resolution generated from NASA-EOSDIS was used to determine the monthly TCI values [38]. Then, the NDVI and LST were used to calculate NVSWI to determine the frequency of drought. The monthly rainfall products $3 \mathrm{~B} 43$ of the TRMM datasets with $0.25^{\circ} \times 0.25^{\circ}$ spatial resolution were generated from NASA-EOSDIS. The 3B43 datasets were resampled to $1 \mathrm{~km}$ spatial resolution to determine the monthly PCI values [52-54]. The monthly GLDAS-2.1 Noah 0.25 degree from 2002 to 2018 was obtained from Giovanni (https://giovanni.gsfc.nasa.gov/giovanni/). The Soil moisture datasets were resampled to $1 \mathrm{~km}$ spatial resolution and used to determine the monthly SMCI values [55,56]. Land cover classification images produced by Henchiri et al. [48] with $1 \mathrm{~km}$ spatial resolution were used in this study (Figure 2).
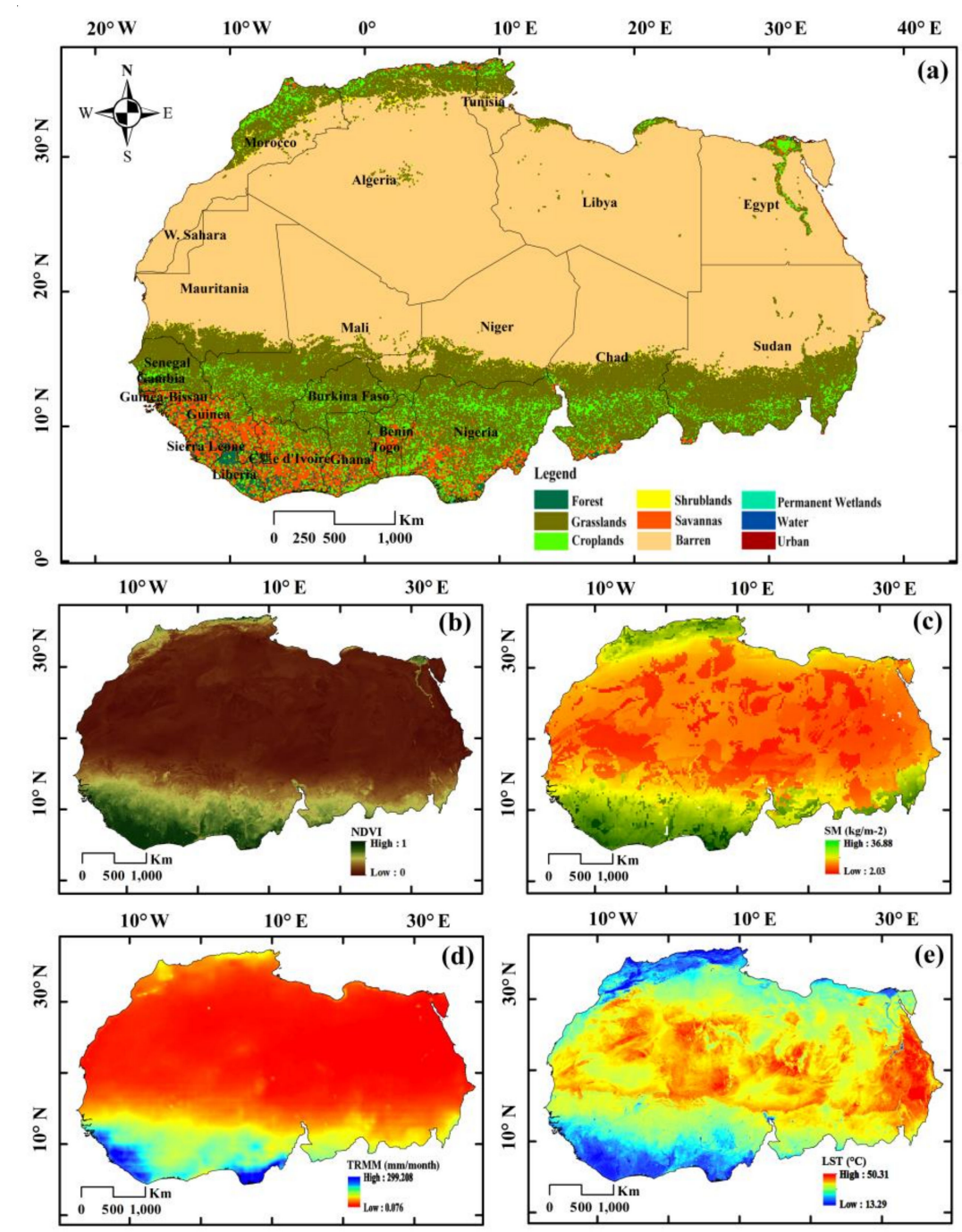

Figure 2. (a) Map of land cover classification, (b) average NDVI, (c) average soil moisture, (d) average precipitation, and (e) average temperature from 2002 to 2018.

This study aims to integrate a multi-source remote sensing dataset to assess the spatiotemporal patterns of drought and the impact on vegetation. But various remote sensing datasets cannot be directly synthesized and compared with each other. Therefore, the multi-source remote sensing data 
should be deduced and scaled to a series of standardized drought parameters. Figure 3 shows the research flowchart.

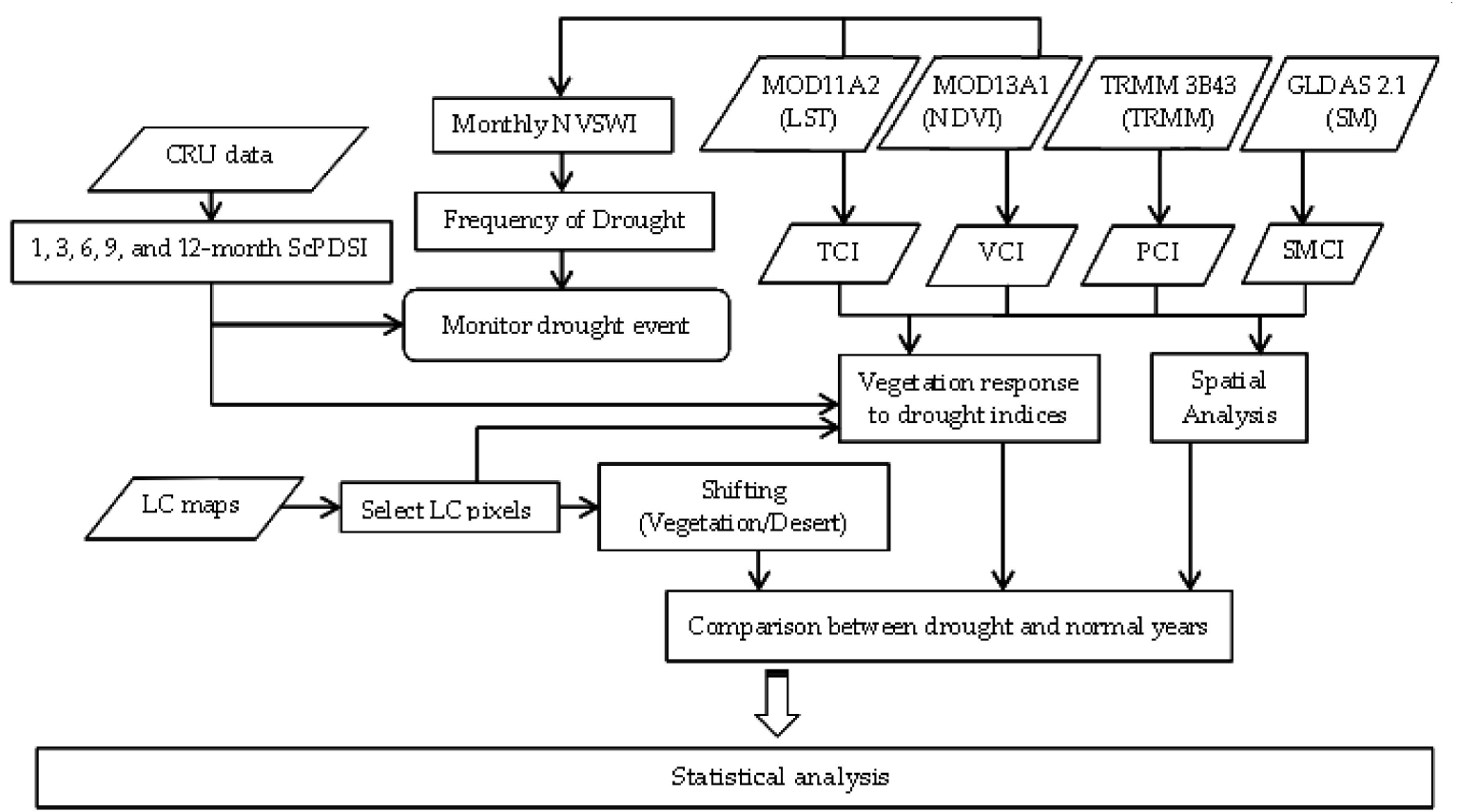

Figure 3. Flowchart of comprehensive drought monitoring based on multi-source remote sensing data.

\section{2. scPDSI (Self-Calibrating Palmer Drought Severity Index)}

The scPDSI index was developed by Wells et al. [28]. The scPDSI is a variant on the original PDSI of Palmer [23], with the aim to make the results of different climate regimes more comparable (Table 1). The PDSI is used to express the severity of drought in a period when the water supply in an area is continually below normal and can be described as [23]:

$$
X_{i}=0.897 X_{i-1}+\frac{1}{3} Z_{i}
$$

where $Z_{i}$ and $X_{i}$ are the moisture anomaly and PDSI indices for the $i$ month.

Table 1. Classification of scPDSI drought categories.

\begin{tabular}{cc}
\hline PDSI & Class \\
\hline-0.49 to -0.99 & Incipient drought \\
\hline-1.00 to -1.99 & Mild drought \\
\hline-2.00 to -2.99 & Moderate drought \\
\hline-3.00 to -3.99 & Severe drought \\
\hline$\leq-4.0$ & Extreme drought \\
\hline
\end{tabular}

As with the PDSI, the scPDSI is determined from time series of temperature $\left({ }^{\circ} \mathrm{C}\right)$ and precipitation (mm/month), together with parameters related to the surface/soil characteristics in each region. The PDSI used here is after self-calibration, the scPDSI. The improvement of scPDSI is how to get the 
climate characteristic coefficient, i.e., the K value. PDSI has derived the following Equations (2) and (3) for $\mathrm{K}$, where $K^{\prime}$ is PDSI general estimation for the climate characteristic of a region [23].

$$
\begin{gathered}
K^{\prime}=1.5 \log _{10}\left[\frac{\left(\frac{\overline{P E}+\bar{R}+\overline{R O}}{\bar{P}+\bar{L}}+2.80\right)}{\bar{D}}\right], \\
K=\frac{17.67}{\sum_{1}^{12} \overline{D K^{\prime}}} K^{\prime},
\end{gathered}
$$

where $\bar{D}$ the average moisture departure, $\bar{L}$ the average moisture loss of soil, $\bar{P}$ the average precipitation, $\overline{R O}$ the average runoff, $\bar{R}$ the average moisture supply of soil, and $\overline{P E}$ is the average potential evapotranspiration.

Equation (3) is used to correct the $K^{\prime}$ value; the value 17.67 is an empirical coefficient [23]. In the scPDSI, $f c$ is defined as the possibility of extreme drought. According to the PDSI classification scales, $f c$ corresponds to a PDSI of 4 , and $(100-f c)$ is called the case of a very wet condition which corresponds to a PDSI of 4 . If we let $f \mathrm{c}$ be $2 \%$, the climate characteristic coefficient $\mathrm{K}$ can be expressed as Wells et al. [28]:

$$
K=\left\{\begin{array}{c}
K^{\prime}\left(-4 / 2^{n d} \text { percentille, }(D<0)\right. \\
K^{\prime}\left(-4 / 98^{n d} \text { percentille, }(D \geq 0)\right.
\end{array}\right.
$$

This self-calibrating method uses the PDSI classification threshold and the original Palmer index to correct $\mathrm{K}$. The method eliminates the limitation of the moisture anomaly $D K^{\prime}$ average of the finite numbers of stations selected in the correction of K (in Equation (3), 17.67 is the empirical coefficient), precisely reflecting the relationship between the studied climate region and the defined PDSI perimeter. Therefore, it is reasonable to use the self-calibration to correct K [28].

\subsection{TRMM Precipitation}

The monthly rainfall product $3 \mathrm{~B} 43(\mathrm{~mm} / \mathrm{h})$ of the TRMM dataset with $0.25^{\circ} \times 0.25^{\circ}$ spatial resolution, stretching from the latitude $50^{\circ} \mathrm{S}$ to $50^{\circ} \mathrm{N}$ was used. The $3 \mathrm{~B} 43$ datasets were resampled to $1 \mathrm{~km}$ spatial resolution and used to calculate the PCI following the Equation (5) [38]:

$$
\mathrm{PCI}=\frac{\mathrm{TRMM}_{\mathrm{i}}-\mathrm{TRMM}_{\min }}{\mathrm{TRMM}_{\max }-\mathrm{TRMM}_{\min }},
$$

where $\mathrm{TRMM}_{\min }$ and $\mathrm{TRMM} \mathrm{M}_{\max }$ represent the minimum and maximum historical values at every chosen time during the study period, and $\mathrm{TRMM}_{\mathrm{i}}$ represents the precipitation in i month.

\subsection{NDVI and LST}

The LST dataset (MOD11A2, 8-day, $1 \mathrm{~km}$ spatial resolution) and the NDVI standard product (MOD13A1, $500 \mathrm{~m}$ ) were obtained from NASA-EOSDIS from 2002 to 2018. The MOD13A1, resampled to $1 \mathrm{Km}$ spatial resolution and the MOD11A2 were used to determine monthly TCI and VCI values following the equations (6) and (7) [38]:

$$
\begin{gathered}
\mathrm{TCI}=\frac{\mathrm{LST}_{\max }-\mathrm{LST}_{\mathrm{i}}}{\mathrm{LST}_{\max }-\mathrm{LST}_{\text {min }}}, \\
\mathrm{VCI}=\frac{\mathrm{NDVI}_{\mathrm{i}}-\mathrm{NDVI}_{\text {min }}}{\mathrm{NDVI}_{\max }-\mathrm{NDVI}_{\text {min }}},
\end{gathered}
$$

$\mathrm{LST}_{\max }\left(\mathrm{NDVI}_{\max }\right)$ and $\mathrm{LST}_{\min }\left(\mathrm{NDVI}_{\min }\right)$ are the maximum and minimum values, respectively, while at every chosen time during the study period, $\mathrm{NDVI}_{\mathrm{i}}$ and $\mathrm{LST}_{\mathrm{i}}$ characterize NDVI and LST in i month. 


\subsection{SM (Soil Moisture)}

Based on the monthly GLDAS-2.1 Noah 0.25 degree datasets from 2002 to 2018 resampled to $1 \mathrm{~km}$, the monthly SMCI values were determined as developed by Kogan [38], as following the Equation (8):

$$
\mathrm{SMCI}=\frac{\mathrm{SM}_{\mathrm{i}}-\mathrm{SM}_{\min }}{\mathrm{SM}_{\max }-\mathrm{SM}_{\min }}
$$

where $\mathrm{SM}_{\min }$ and $\mathrm{SM}_{\max }$ are the minimum and maximum values at every chosen time during the study period, $\mathrm{SM}_{\mathrm{i}}$ is the soil moisture in i month.

\subsection{NVSWI (Normalized Vegetation Supply Water Index)}

When the vegetation experiences a dry season and a water shortage, the leaf stomata will close to maintain the water. Consequently, LST increases, and evapotranspiration decreases. Due to evapotranspiration, the LST observed on vegetation would be lower than that observed on bare ground. Equation (9) is used by Abbas et al. [57] to determine NVSWI values.

$$
\mathrm{VSWI}=\frac{\mathrm{NDVI}}{\mathrm{LST}}
$$

Since the Vegetation Supply Water Index (VSWI) can characterize the relative spatial area and isn't identical on the time series, the NVSWI has been advanced and determined using the following equation [57]:

$$
\mathrm{NVSWI}=\frac{\mathrm{VSWI}_{\mathrm{i}}-\mathrm{VSWI}_{\min }}{\mathrm{VSWI}_{\max }-\mathrm{VSWI}_{\min }},
$$

where VSWI $\mathrm{Vax}_{\max }$ and $\mathrm{VSWI}_{\min }$ are maximum and minimum VSWI, respectively, at every chosen time during the study period. Abbas et al. [57] provided five intensity categories to classify NVSWI values, as shown in Table 2.

Table 2. Drought categories for NVSWI.

\begin{tabular}{cccccc}
\hline & Severe & Moderate & Slight & Normal & Wet \\
\hline NVSWI & $<0.20$ & $0.20-0.40$ & $0.40-0.60$ & $0.60-0.80$ & $>0.80$ \\
\hline
\end{tabular}

\subsection{Drought Frequency}

In this study, we used the NVSWI maps to calculate the frequency of drought, each map was reclassified into the Boolean image, and 17 binary maps are created for each of the drought severity classes. These maps for 17 years are added to get the frequency of Normal, Slight, Moderate, and Severe drought at each pixel level. Then, different drought frequency levels $(F)$ over the study regions from 2002 to 2018 were calculated using the following formula [58].

$$
F_{i}=\frac{n_{i}}{N} 100,
$$

where $F_{i}$ is the drought frequency for each $i$ drought level $i, n_{i}$ is how many times $i$ level of drought happened at this grid cell during the 17 years, and $N$ is the length of the study period (17 years). 


\subsection{Tendency Rate of Drought}

To analyze whether the drought was increasing or decreasing from 2002 to 2018 in the study region, the tendency rate of the drought was determined based on the monthly NVSWI data. It was calculated following Equation (12) [58]:

$$
\text { Slope }=\frac{n \sum_{i}^{n}\left(i \times F_{i}\right)-\left(\sum_{i=1}^{n} i\right) \times\left(\sum_{i=1}^{n} F_{i}\right)}{n \sum_{i=1}^{n} i^{2}-\left(\sum_{i=1}^{n} i\right)^{2}}
$$

where $F_{i}$ is the frequency of droughts occurring in the $i_{\text {th }}$ year, $i$ is the series number of the year, and $n$ is the length of time series. When the slope presents negative values, it showed that the degree of drought increased over the time-series. The positive slope means that the frequency of drought increases, and the degree of drought worsens over the time series.

\subsection{Selection of Land Cover Pixels}

Land cover maps between 1982 and 2015 over North and West Africa (NW Africa) produced by Henchiri et al. [48] were utilized to locate the dominant land cover's pixels representing Evergreen Broadleaf Forest, Grasslands, Croplands, and Savannas (Table 3). A shape file containing polygons with $1 \mathrm{~km}$ was made in the GIS, to link these datasets to $1 \mathrm{~km}$ MODIS data, where every polygon with $1 \mathrm{~km}$ corresponds to a pixel in the scPDSI, PCI, TCI, VCI, and SMCI images. Then, the LC layers were superimposed on the polygon layer, and the responses of every type of LC to the drought indices were determined.

Table 3. Land cover classes and areas.

\begin{tabular}{ccc}
\hline \multirow{2}{*}{ Map Unit } & \multicolumn{2}{c}{ Area } \\
\cline { 2 - 3 } & $\mathbf{K m}^{\mathbf{2}}$ & $\mathbf{\%}$ \\
\hline Evergreen Broadleaf Forest & $15,9132.1$ & 0.92 \\
\hline Deciduous Broadleaf Forest & 9208.81 & 0.05 \\
\hline Open Shrublands & $182,273.2$ & 1.05 \\
\hline Woody Savannas & $118,926.6$ & 0.69 \\
\hline Savannas & $943,824.9$ & 5.45 \\
\hline Grasslands & $3,201,880$ & 18.48 \\
\hline Permanent Wetlands & $13,888.51$ & 0.08 \\
\hline Croplands & $1,351,932$ & 7.8 \\
\hline Urban and Built-up & 9331.29 & 0.05 \\
\hline Barren or Sparsely Vegetated & $11,337,555$ & 65.43 \\
\hline Water & 604.58 & 0.001 \\
\hline Total area & $17,328,557$ & 100 \\
\hline
\end{tabular}

A total of 434 LC pixels, with over $89 \%$ of the pixel area corresponding to the same LC type were chosen over all the study period. The $89 \%$ threshold was selected to identify the homogeneous pixels, which could reduce the impact of different targets present in the pixel from thermal signals and LC reflectance. The selection of LC pixels is based on taking into account that the thermal signature and multi-temporal spectra of the same LC can have a similar seasonal pattern. Figure 4 present the location of the chosen pixels over the study region. Their spatial distribution indicates that the pixels of Evergreen Broadleaf Forest are mostly concentrated in the S-W part over the study regions, those of Croplands principally situated in the south and north parts over the study regions. Grasslands are 
located in the S-W, S-E, and N-W parts of the study regions. Savannas pixels were only found in the $\mathrm{S}-\mathrm{W}$ of the study regions.

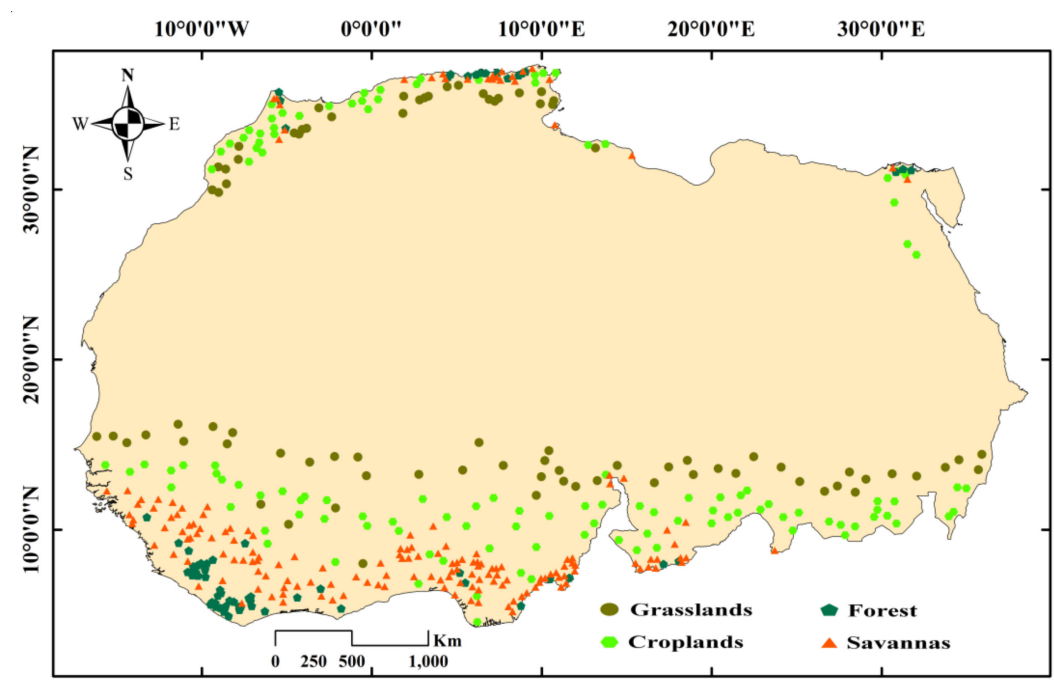

Figure 4. Location of selected major LC pixels.

\section{Results}

\subsection{Drought in North and West Africa during 2002-2018}

Figure 5 presents the temporal variation of scPDSI at five different timescales across the study area. The figure below shows that the drought intensity is decreased with the increase in the timescale. However, the drought events occurred in years 2002, 2009, 2010, and 2016 the scPDSI were below the-ve 2 at all timescales of scPDSI. The years 2014 and 2015 were normal, scPDSI values above the-ve 0.49 for all timescales. The severity of the dry and normal years is higher than the other years; Therefore, these years were selected for further investigation.

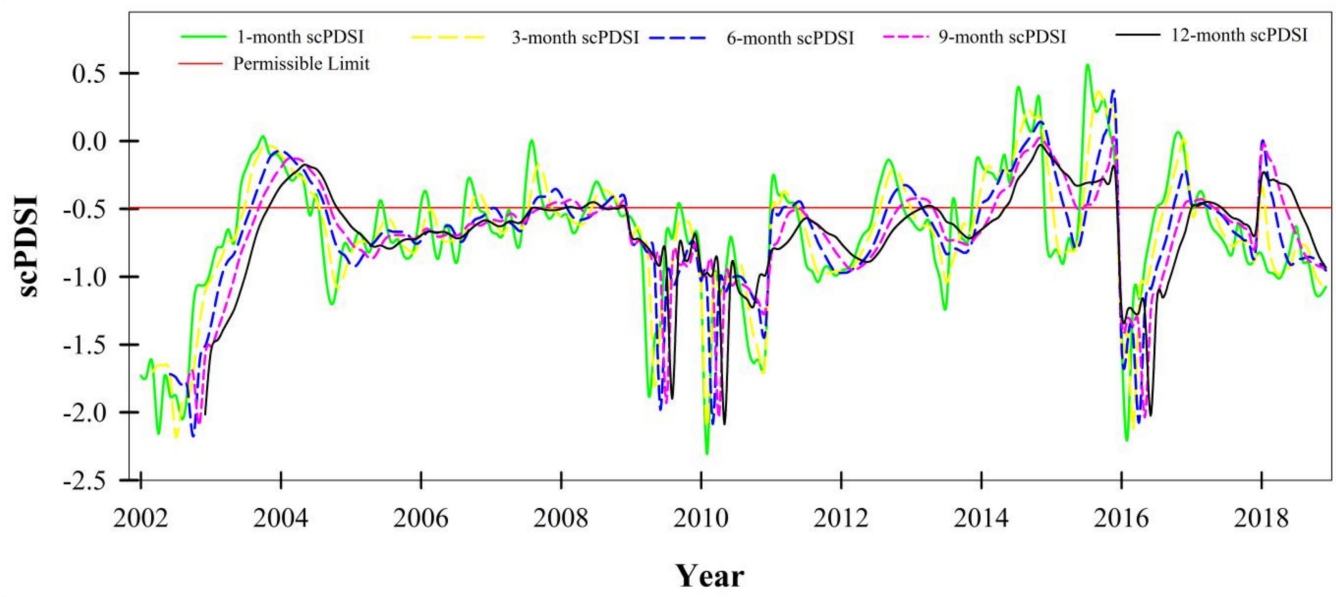

Figure 5. Trend of monthly scPDSI over North and West Africa from 2002 to 2018.

Furthermore, monthly NVSWI data was used to determine the frequency of drought between 2002 and 2018 in the study region (Figure 6). Based on the analysis of scPDSI at different timescale trend and the frequency of drought, we selected four dry years (2002, 2009, 2010 and 2016) and two normal years (2014 and 2015) to evaluate the spatiotemporal pattern of PCI, SMCI, VCI, and TCI indices for drought monitoring over NW Africa. The highest drought frequency was observed during 2010 $(86.59 \%)$, the lowest drought frequency was obtained during 2014 (74.86\%) and 2015 (74.80\%). Figure 7 
shows the drought change trend in the study area during the study period. The drought especially affected especially the Sub-Saharan region, as reported by Ahmadalipour and Moradkhani [39].

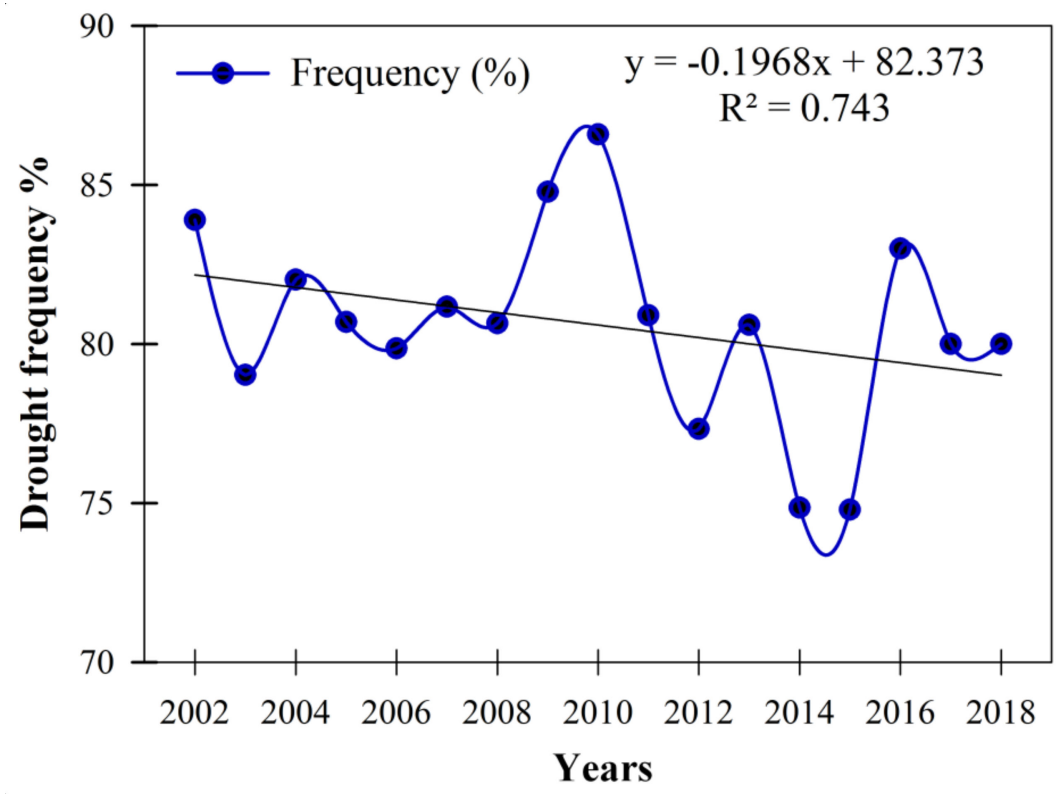

Figure 6. Trend of drought frequency over North and West Africa from 2002 to 2018.

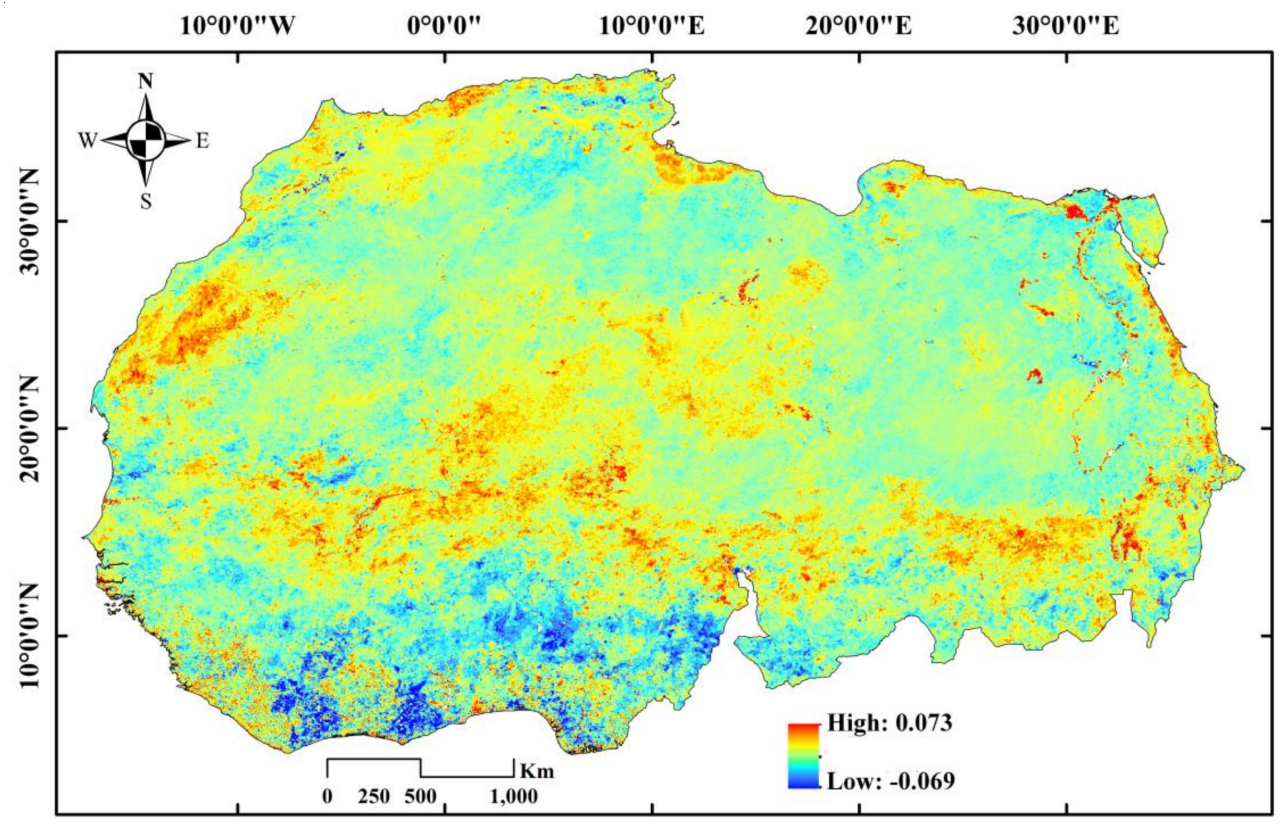

Figure 7. Distribution of the drought change trend over North and West Africa from 2002 to 2018.

\subsection{Shifting between Vegetation and Desert During Dry and Normal Years}

Figure 8 shows the spatial pattern of shifting for four dry years and two normal years, and the amount of change between vegetation and desert from 2002 to 2018. We choose to study only the selected years to compare the shifting between vegetation and desert during dry and normal years. The lines for each year indicate the boundary of desert and vegetation for the corresponding year. Further, a dry year (2002) was selected as the base map underneath. In Figure 8a, only two occurring classes were found, the desert and vegetation. It is clear that during the dry years, the desert has been shifted toward vegetation area, while during normal years, the latter turns back into a desert. The difference in terms of vegetation changes during 2008/2009, 2009/2010, 2013/2014 and 2014/2015 were 
$-45,974 \mathrm{Km}^{2},-33,727 \mathrm{Km}^{2}, 59,866 \mathrm{Km}^{2}$ and $48,765 \mathrm{Km}^{2}$, respectively. Meanwhile, for the desert during 2008/2009, 2009/2010, 2013/2014 and 2014/2015 were 45,815 $\mathrm{Km}^{2}, 34,074 \mathrm{Km}^{2},-59,901 \mathrm{Km}^{2}$ and $-48,828$ $\mathrm{Km}^{2}$, respectively (Figure $8 \mathrm{~b}$ ). This indicated that the conversion, from vegetation to desert in West region, is related to normal monsoon rainfall, particularly in summer, providing enough precipitation for vegetation growth in the region. However, in North region, this conversion could be the consequence of solid nonlinear interactions among the atmosphere and vegetation types [59]. Though their rapid occurrence, these shifts are probably made by moderate changes in basic ecological situations, related to the arriving solar radiation, the degree of land degradation, or the surface temperatures $[60,61]$.

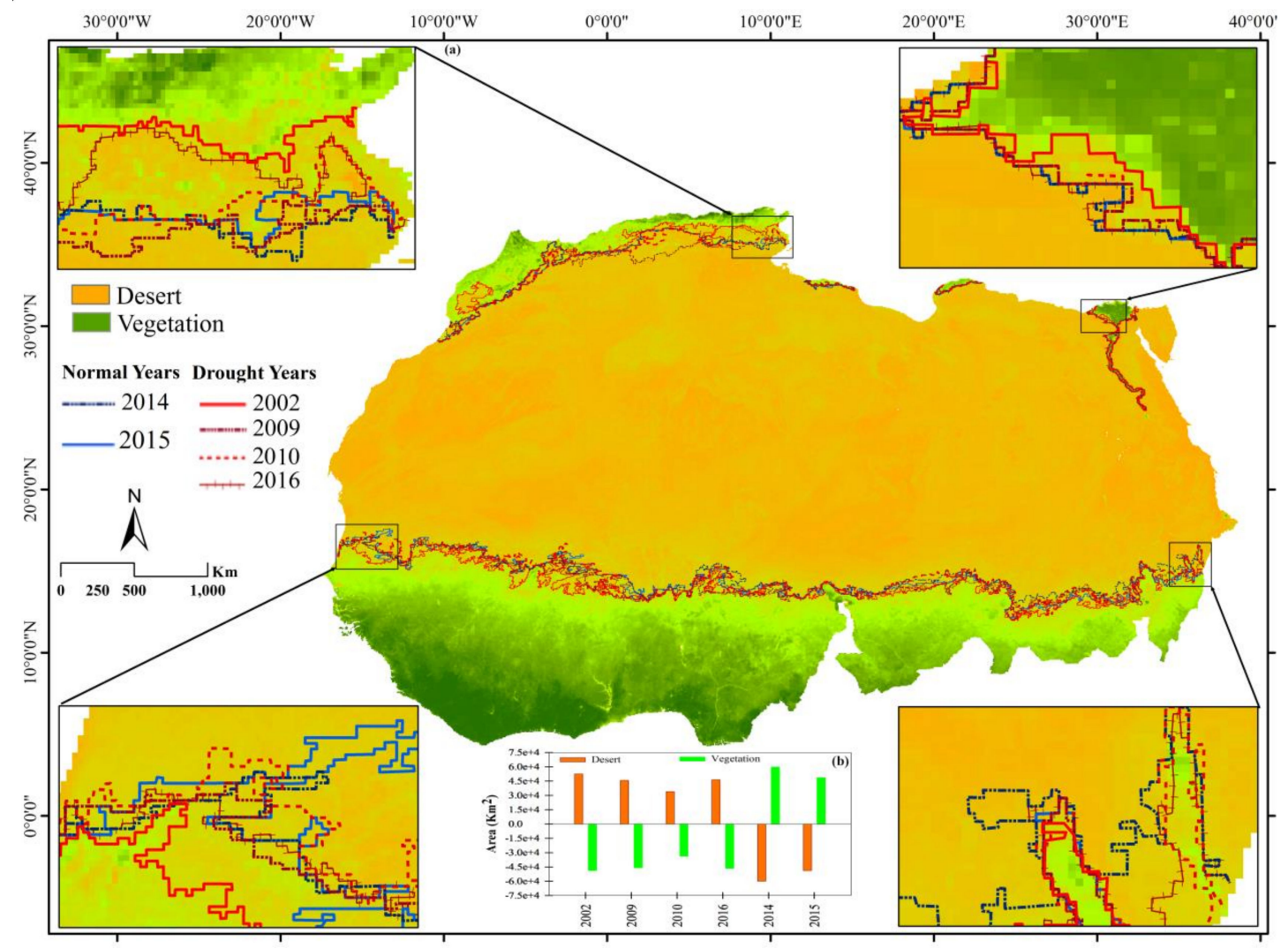

Figure 8. Shifting between vegetation and desert. (a): spatial pattern of shifting in normal and dry years, $(\mathbf{b})$ : the amount of change between vegetation and desert during the selected years.

\subsection{Temporal and Spatial Comparisons of Remote Sensing Drought Indices}

The temporal variations of monthly PCI, SMCI, TCI, and VCI from 2002 to 2018 over (NW) regions are compared for different LC types (Figure 9a). Generally, the more drought events occurred in the summer season in the North region, while in the West region in the winter season. The findings are logical, in the North region during the summer less precipitation occurred than the West region [11-15]. The PCI, SMCI, TCI, and VCI curves show randomly according to different land cover. For example, PCI values for Forest land ranged between $0-1.0$ and for Grasslands between the 0-0.8 for both (NW) regions. Similarly, for Savannas' SMCI ranged between 0.1 to 0.9 , and for the Grasslands 0.1-0.8. The remote sensing based vegetation index (VCI) highest values were obtained for Savannas followed by Croplands, Forest and Grasslands. However, there was clear evidence of how the vegetation effect in the drought event occurred. For example, in extreme drought year 2011, the VCI across the Forest and Grasslands, the VCI value reached 0 to 0.4 , wherein normal year between the ranges of 0.2 to 0.9 , especially in the North region. 


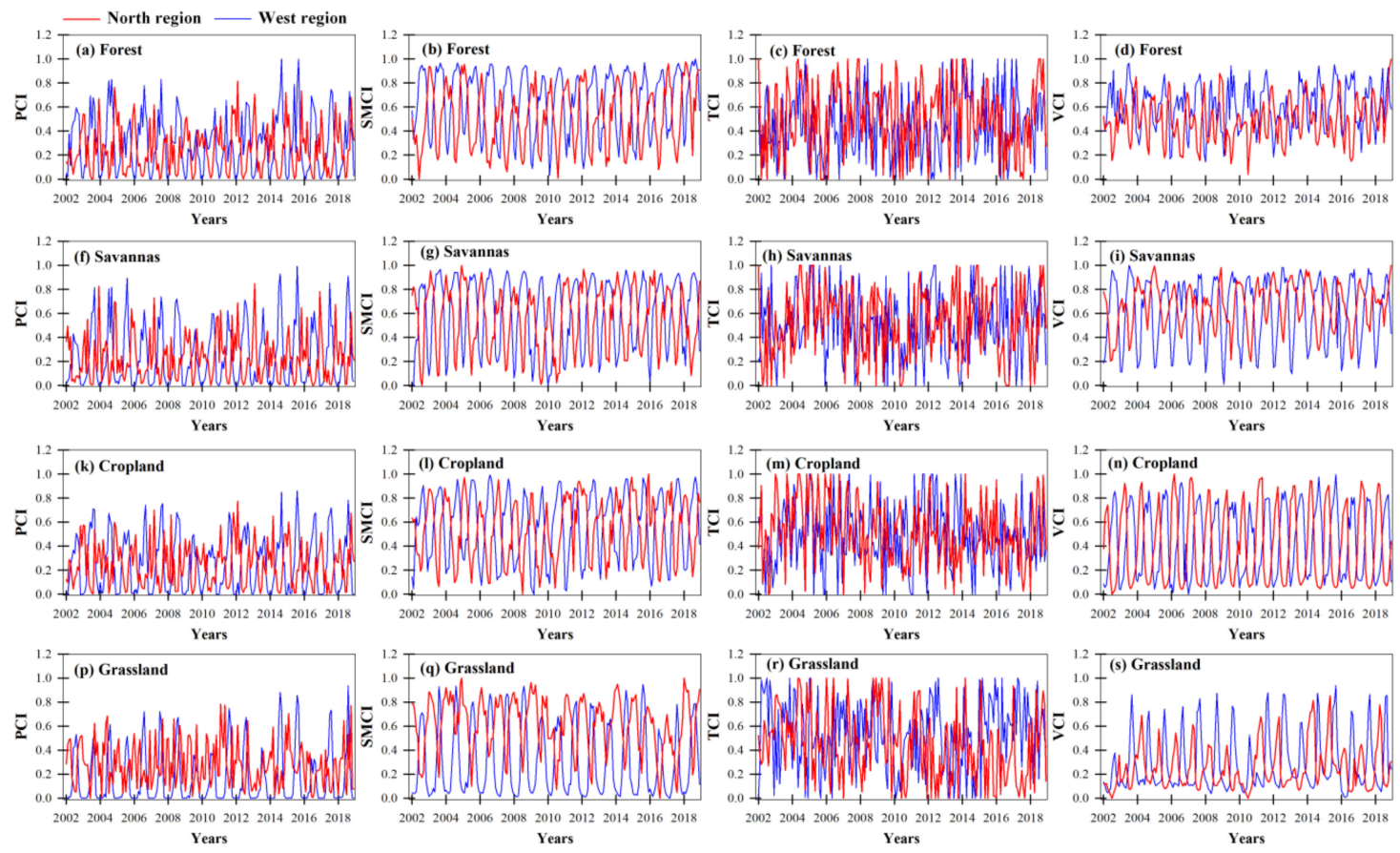

(a)

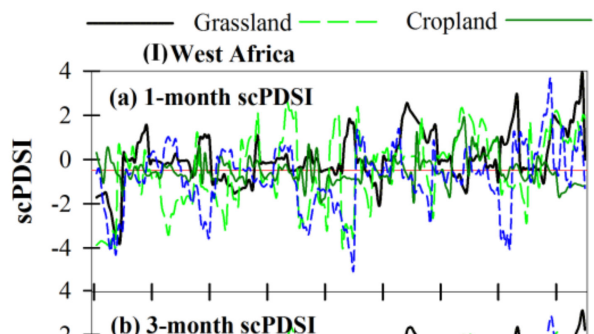

Forest------ Savannas $\longrightarrow$ Permissible Limit

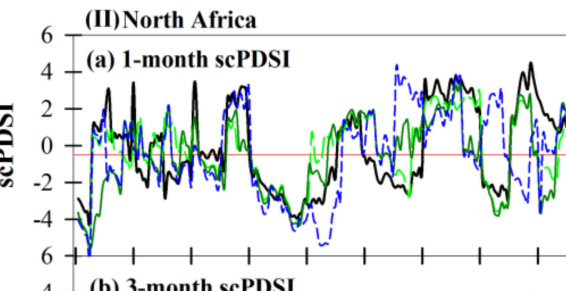

(b) 3-month scPDSI

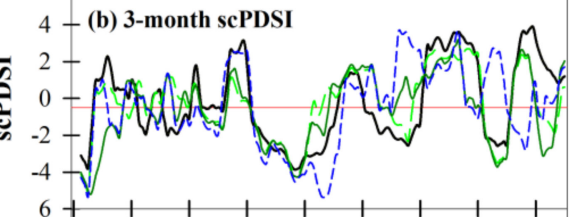

(c) 6-month scPDSI
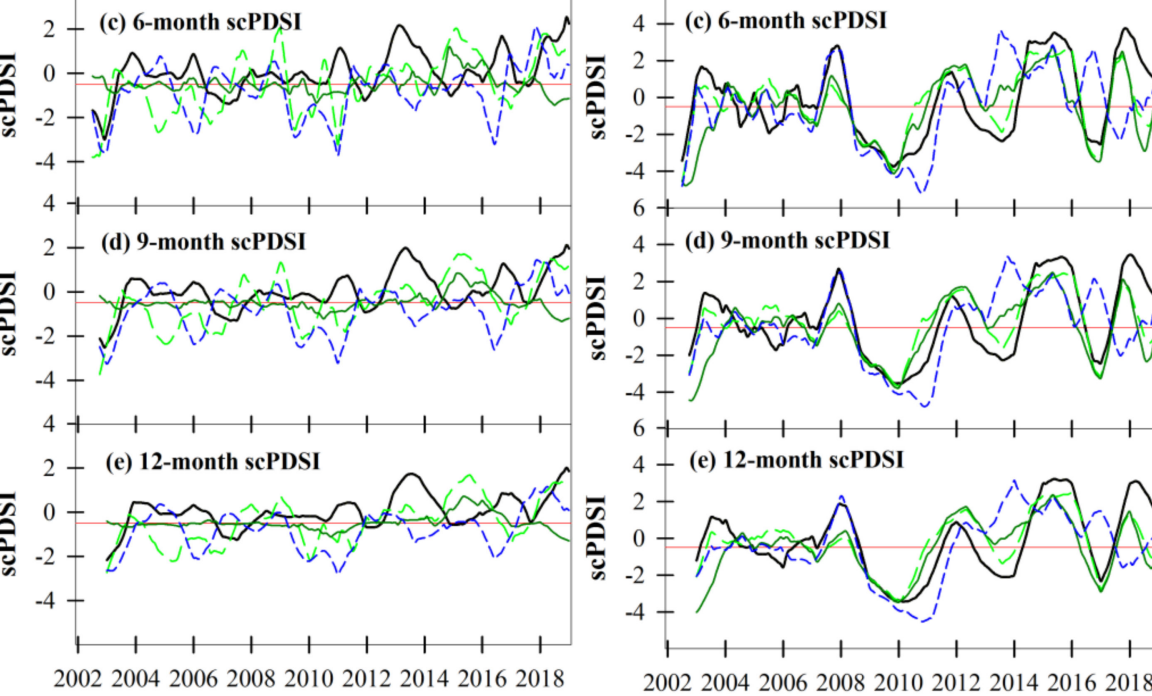

$$
6+1+1,1
$$
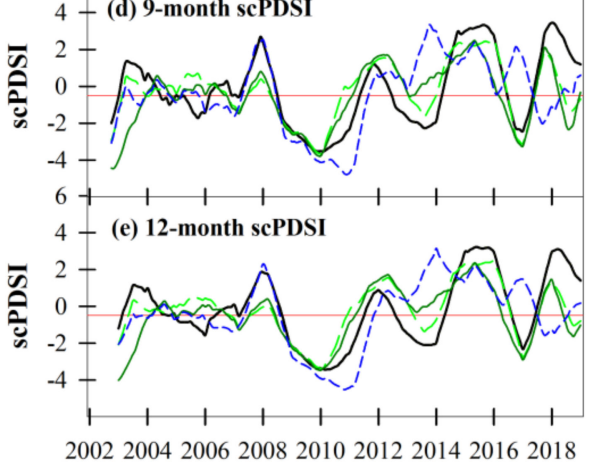

Year

Year

(b)

Figure 9. (a) Trends of monthly PCI, SMCI, TCI, and VCI for Forest, Savannas, Croplands and Grasslands over North and West Africa from 2002 to 2018; (b) Trends of scPDSI 1, 3, 6, 9, and 12 for Forest, Savannas, Croplands and Grasslands over North and West Africa from 2002 to 2018. 
Figure $9 \mathrm{~b}$ shows the response of Grasslands, Croplands, Savannas, and Forest to scPDSI with one-, three-, six-, nine-, and 12-month timescales and witnessed the dry/wet presence with inter-seasonal variability ranging between -4 and 4 . In the West region, Grasslands, Croplands and Savannas experienced extreme drought conditions in 2002. In the North region, the four LC types were experienced extreme drought conditions during 2009 and 2010, especially with short-term 1-6 months timescales in both regions (Figure 9b). The finding are consistent with Figure 9a, the years 2002, 2009, 2010, and 2016 were the driest (scPDSI from -2.0 to -4.0) and the years 2014 and 2015 were the wettest (scPDSI > 2.0) over 2002-2018 that were consistent for the four LC types.

The Pearson correlation coefficients were obtained to investigate the correlations between PCI, SMCI, TCI, and VCI with scPDSI a 1-12 month timescale for Grasslands, Croplands, Savannas, and Forest in (NW) regions of the study area (Table 4). Positive correlations were observed among the indices, whereas very low correlation with TCI.

Table 4. Pearson correlation analyses of drought indices (PCI, SMCI, TCI, VCI, and scPDSI-1, 3, 6, 9, and 12) for Grasslands, Croplands, Savannas, and Forest in (NW) Regions of the study area from 2002 to 2018.

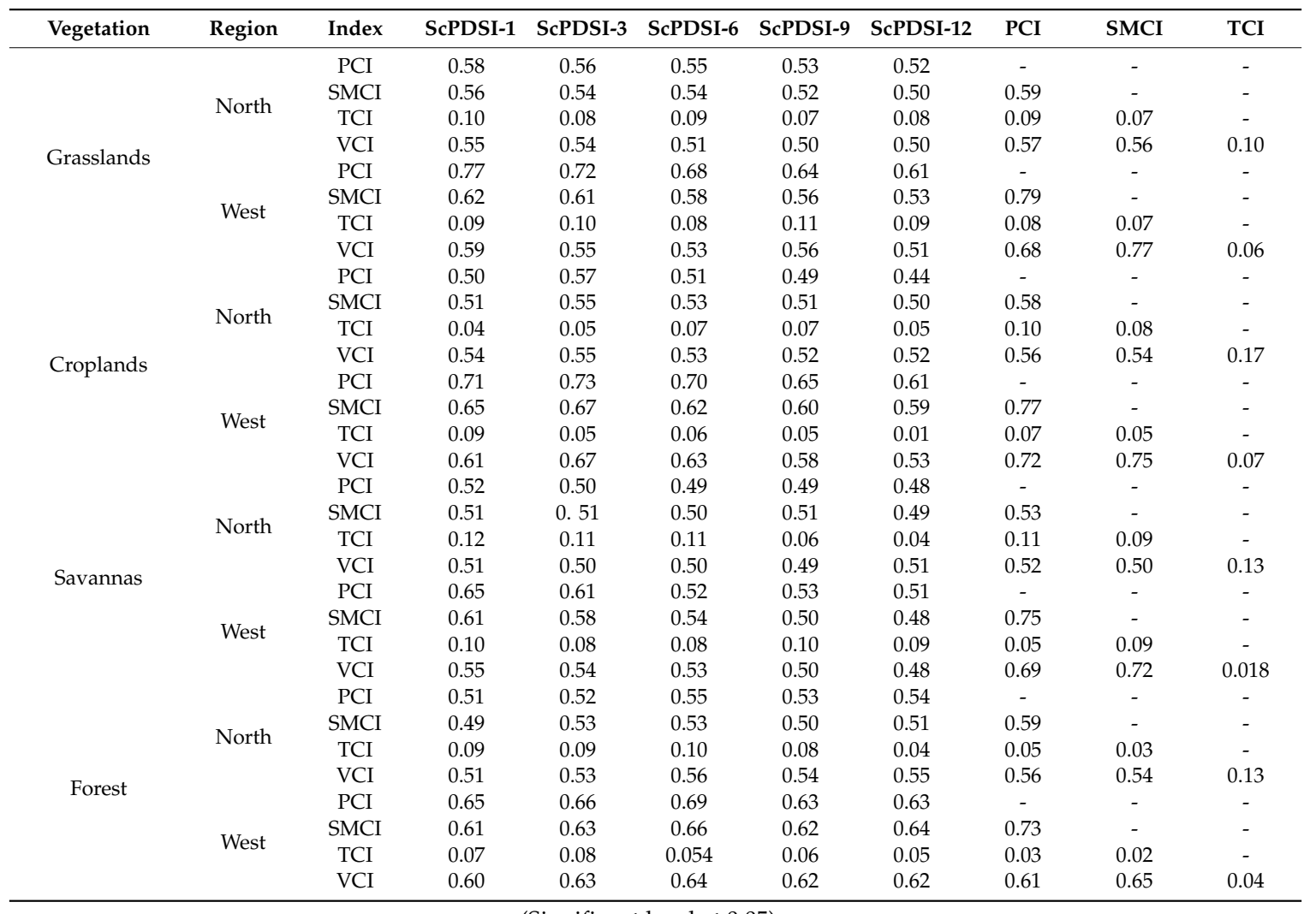

(Significant level at 0.05).

The high correlations were obtained in the West region compared to the North region. For example, the correlations between the pairs of PCI and scPDSI-1, SMCI and PCI, and SMCI and VCI in Grasslands across the West region were 0.77, 0.79, and 0.77, respectively. Further, the correlations between PCI with three-month scPDSI, or SMCI and SMCI and VCI were 0.73, 0.77, and 0.75, respectively. The correlation between PCI with one-month scPDSI or SMCI and SMCI with VCI were 0.65, 0.75, and 0.72 , respectively across the Savannas in West region. For Forest between PCI and six- month scPDSI, or SMCI and, SMCI and VCI were $0.69,0.73$, and 0.65 , respectively. On the other hand, in the North region the correlation between the pairs PCI and one-month scPDSI, SMCI and PCI, and PCI and VCI for the Grassland were 0.58, 0.59, and 0.55, respectively. For Croplands between PCI and 3-scPDSI, or SMCI, and PCI and VCI were $0.57,0.58$, and 0.56 , respectively. Savannas between PCI and 
scPDSI-1, SMCI and PCI, and PCI and VCI were 0.52, 0.53, and 0.50, respectively. For Forest between PCI and six-month scPDSI, SMCI and PCI, and PCI and VCI were 0.55, 0.59, and 0.54, respectively. The lowest correlations $(r<0.2)$ were obtained between TCI and the other indices for the four LC types over (NW) regions.

The classification scheme of Kogan [38] was used in this study to describe the degree of drought. The PCI, SMCI, TCI, and VCI indices are categorized into five classes (Table 5): no drought, abnormally dry, moderate drought, severe drought, and extreme drought (Figure 10, Figure 11, Figure 12, Figure 13). Also, the seasonal averages of PCI, SMCI, TCI, and VCI indices with four extremely dry (2002, 2009, 2010, and 2016) and two normal years (2014 and 2015) were sequentially selected to test the monitoring capability of drought indices. The spatial pattern of PCI index (Figure 10) indicated that an extreme drought occurred in the winter season (DJF) in West region. However, in the North region, the extreme drought occurred during the summer season (JJA), which explains the impact of normal monsoon rainfall in West region during the summer [2]. This provided sufficient rainfall for vegetation growth in West region. The TCI changes considerably during different seasons and shows an extreme drought in 2010 during the winter season DJF (Figure 11). From June to August, the VCI values had progressively expanded, while after August, declined until February, from March to May, they presented a significant decrease (Figure 12). In the middle of May, the VCI values presented a change in vegetation. The SMCI shows an extreme drought during the winter (DJF) and spring (DJF) seasons in West region and African Sahara, and during the summer season (JJA) over the northern part of the study region (Figure 13). The tendency of drought frequency showed that the highest frequency of drought was observed in 2009 and 2010 (Figures 6 and 7), which is in accordance with the results presented in Figure 9, Figure 10, Figure 11, Figure 12, Figure 13. The derived indices have demonstrated a high relevance for spatiotemporal monitoring of drought [34]. Overall, the drought trends are strongly related to vegetation changes over NW Africa, fluctuating along with their spatial distribution and consistent with previous investigations on drought trends.

Table 5. Classification of PCI, SMCI, VCI, and TCI drought indices.

\begin{tabular}{cc}
\hline Drought Indices Values & Drought Conditions \\
\hline$<10$ & Extreme drought \\
\hline $10-20$ & Severe drought \\
\hline $20-30$ & Moderate drought \\
\hline $30-40$ & Abnormal dry \\
\hline$>40$ & No drought \\
\hline
\end{tabular}

\subsection{Vegetation Response to scPDSI, PCI, TCI, VCI and SMCI}

Figure 14 presents the temporal response profiles of the selected LC pixels to scPDSI during a drought year (I) and normal year (II), based on the LC map generated by Henchiri et al. [48] representing Forest, Croplands, Grasslands and Savannas cover types. Though the case is restricted to some pixels (for every vegetation cover type), the response of vegetation, shown by selected pixels of LC types over this period, represented different pixels of vegetation cover types following previous studies [62,63]. During the drought year (Figure 14-I), the Forest in the West region is under mild drought conditions. In the North region, they are under mild drought conditions from January until June and moderate drought conditions during July and August, and no drought conditions from September to December (Figure 14a). Savannas in the West region are under moderate drought conditions from March until August and under severe to extreme drought conditions from October to December. In the North region, they were under Severe to extreme drought conditions (Figure 14b). Croplands in the West region are under severe drought conditions from October until April, and no drought conditions from May until September. In the North region, they are under severe drought conditions in January, from April until June under mild drought conditions, and from July until December under no drought 
conditions (Figure 14c). Grasslands in the West region are under moderate to severe drought conditions from January to August and under mild drought from September to December. In the North region, the Grasslands were under mild drought between April and July (Figure 14d). During the normal year (Figure 14-II), the four LC types in (NW) regions show no drought conditions.

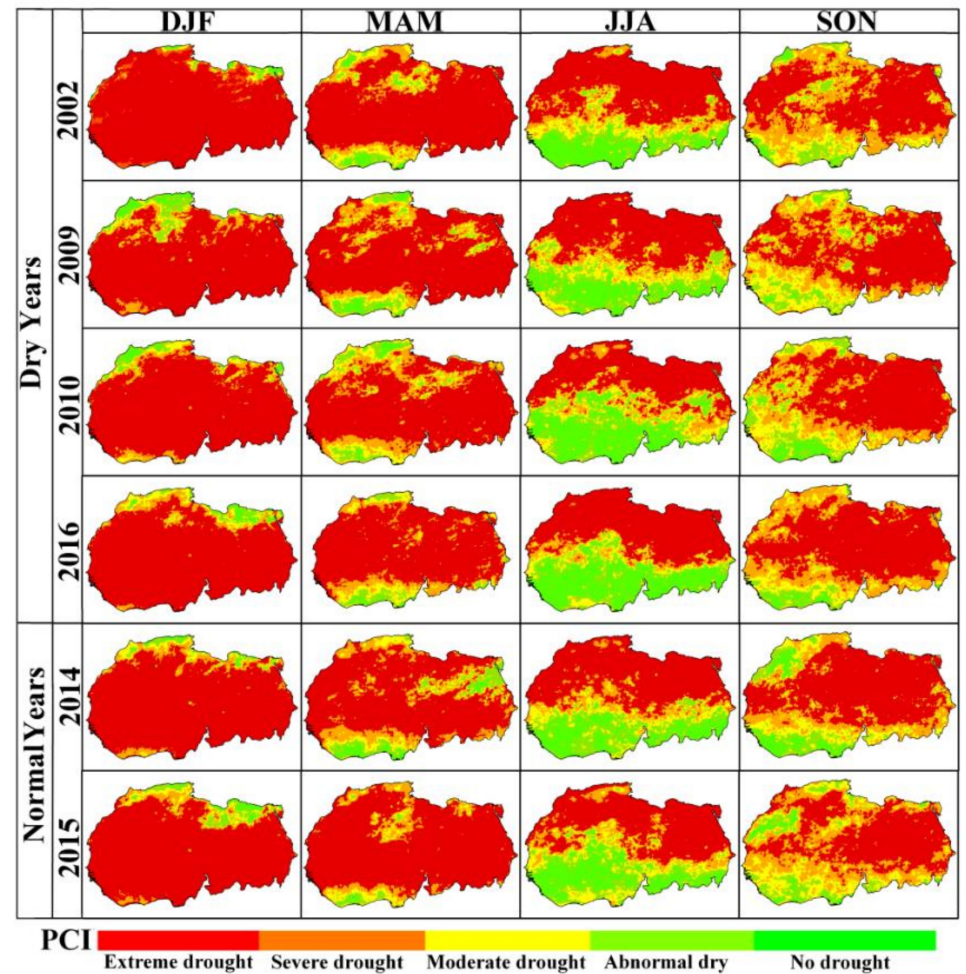

Figure 10. Spatial distribution of seasonal average of PCI in dry and normal years over the study area.

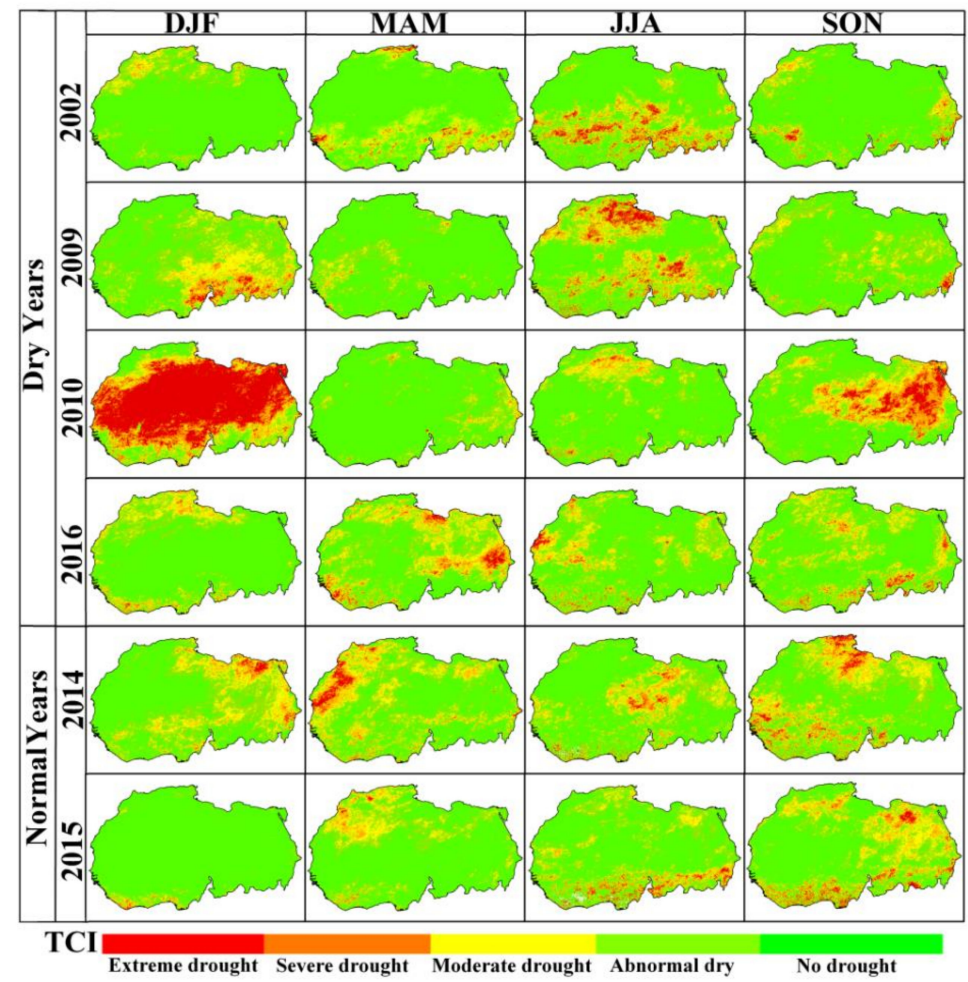

Figure 11. Spatial distribution of seasonal average of TCI in dry and normal years over the study area. 


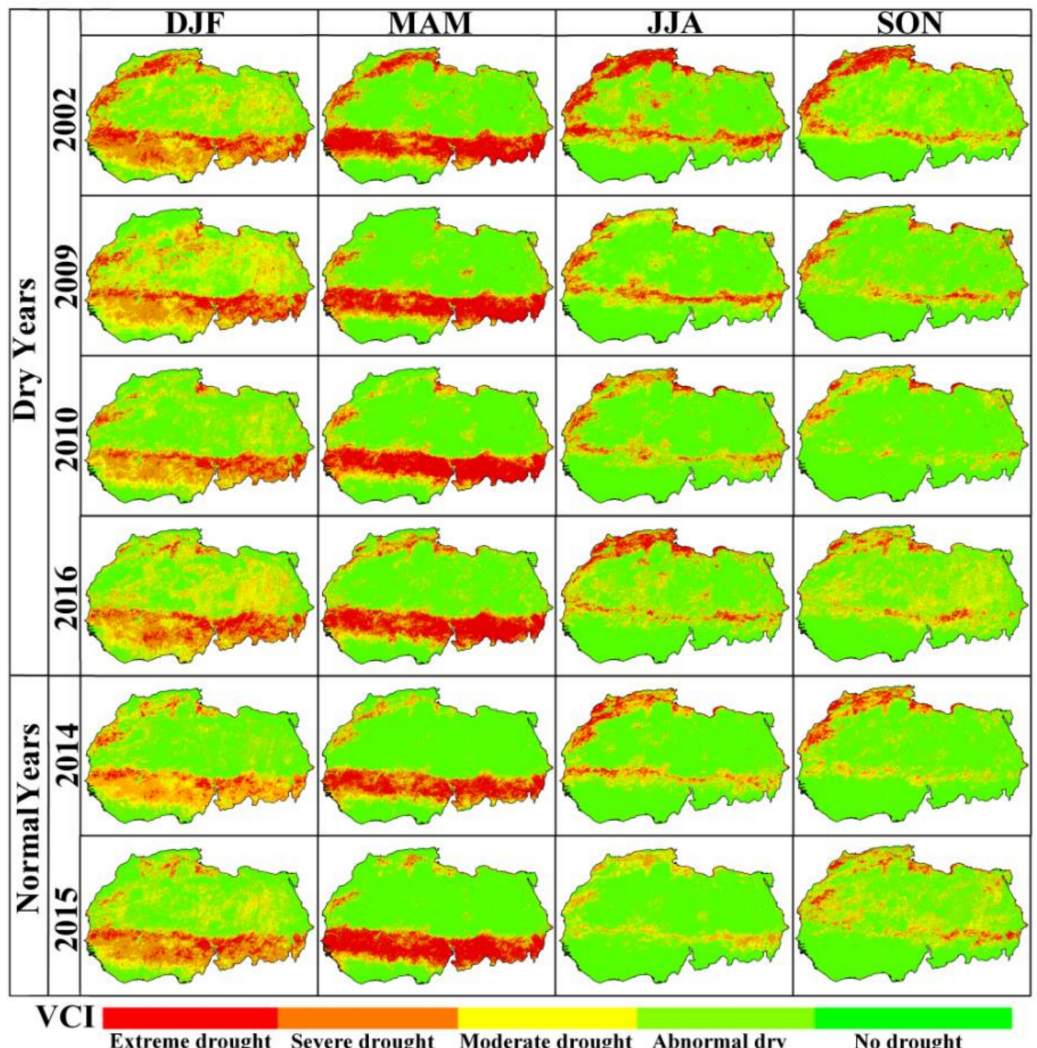

Figure 12. Spatial distribution of seasonal average of VCI in dry and normal years over the study area.

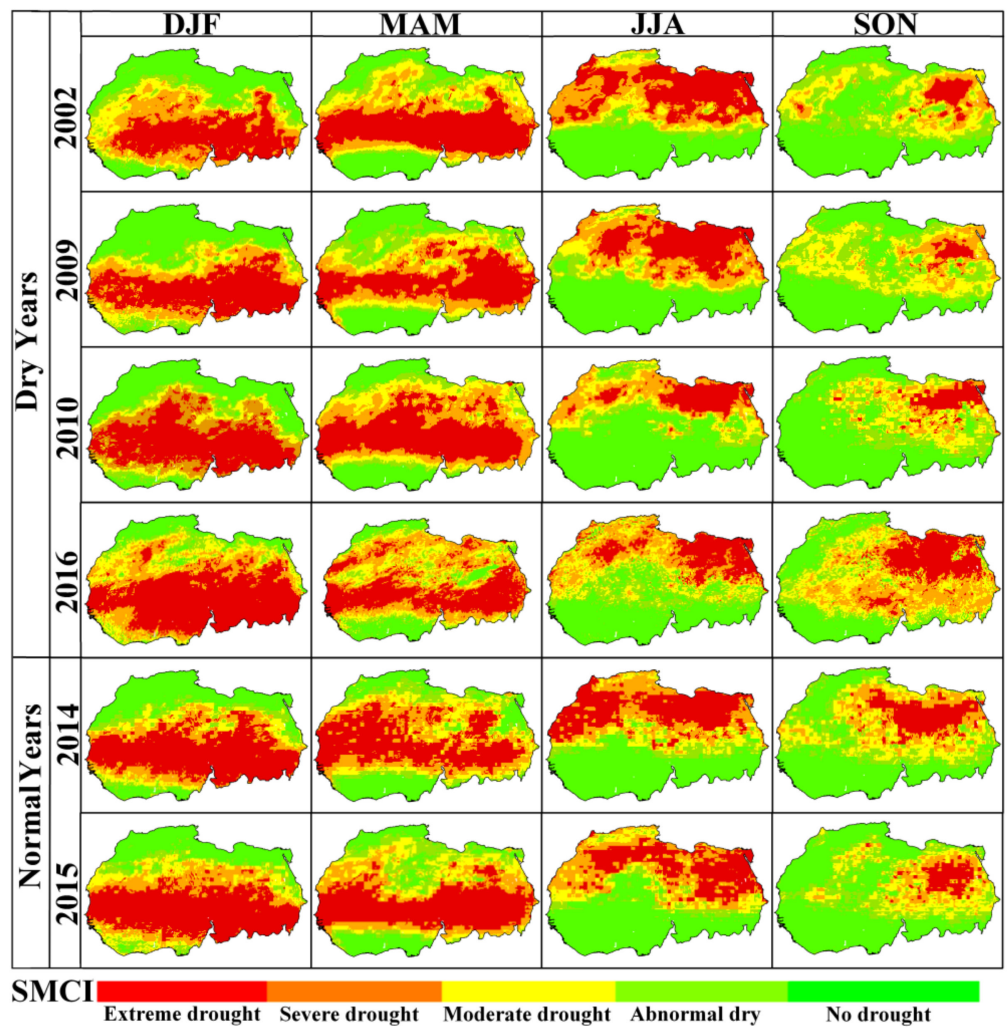

Figure 13. Spatial distribution of seasonal average of SMCI in dry and normal years over the study area. 

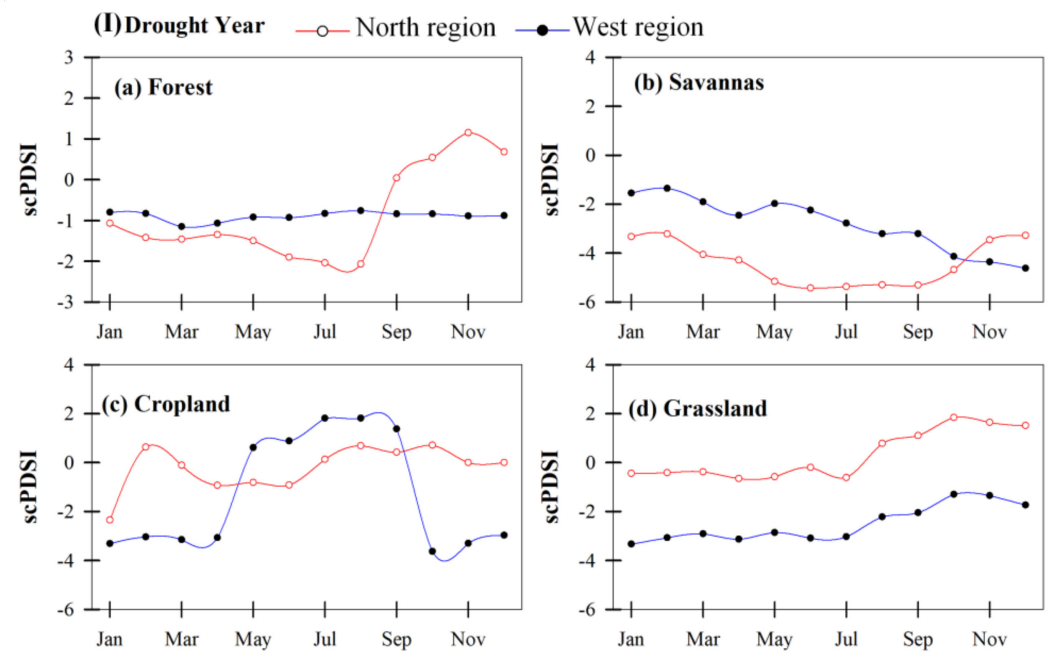

(II) Nomal Year


Figure 14. (a-e) Forest, (b-f) savannas, $(\mathbf{c}-\mathbf{g})$ Croplands, and (d-h) Grasslands response to drought derived from scPDSI.

Figure 15 presents the temporal response profiles of the selected LC pixels to PCI, TCI, VCI, and SMCI in NW regions during a dry year. The trend shows a difference in vegetation responses to drought indices over (NW) regions of the study area. The PCI trend indicates that the four LC types were under severe to extreme drought conditions in the North region from May to August. In the West region, the PCI shows a severe to extreme drought for Forest from November until February, for Savannas and Croplands from October until April, and Grasslands from October until June. SMCI in the North region shows extreme to severe drought conditions for Forest from June to September, for Savannas from May to September, for Croplands and Grasslands during June and July. In the West Region, SMCI displays extreme to severe drought conditions for Forest during February and March, for Savannas from December to April, for Croplands during January and February, and for Grasslands from December to April. The TCI trend shows a variation between extreme drought and no drought, for example, extreme to severe drought conditions were found for Forest in (NW) regions, for Savannas in (NW) regions from May to October, for Croplands from July until December in North region, for Grasslands from April to October in North region, and from January until mid-May in West region. The VCI trend shows no drought conditions for Forest in the West region, and severe to extreme drought conditions from mid-June until August in the North region; for Savannas moderate to severe drought conditions from July to September in the North region, and from January to March in the West region; for Croplands severe to extreme drought conditions from June to November for North 
region, and from December to May in the West region; also severe to extreme drought conditions for Grasslands from June until October in the North region, and from October to July in the West region.
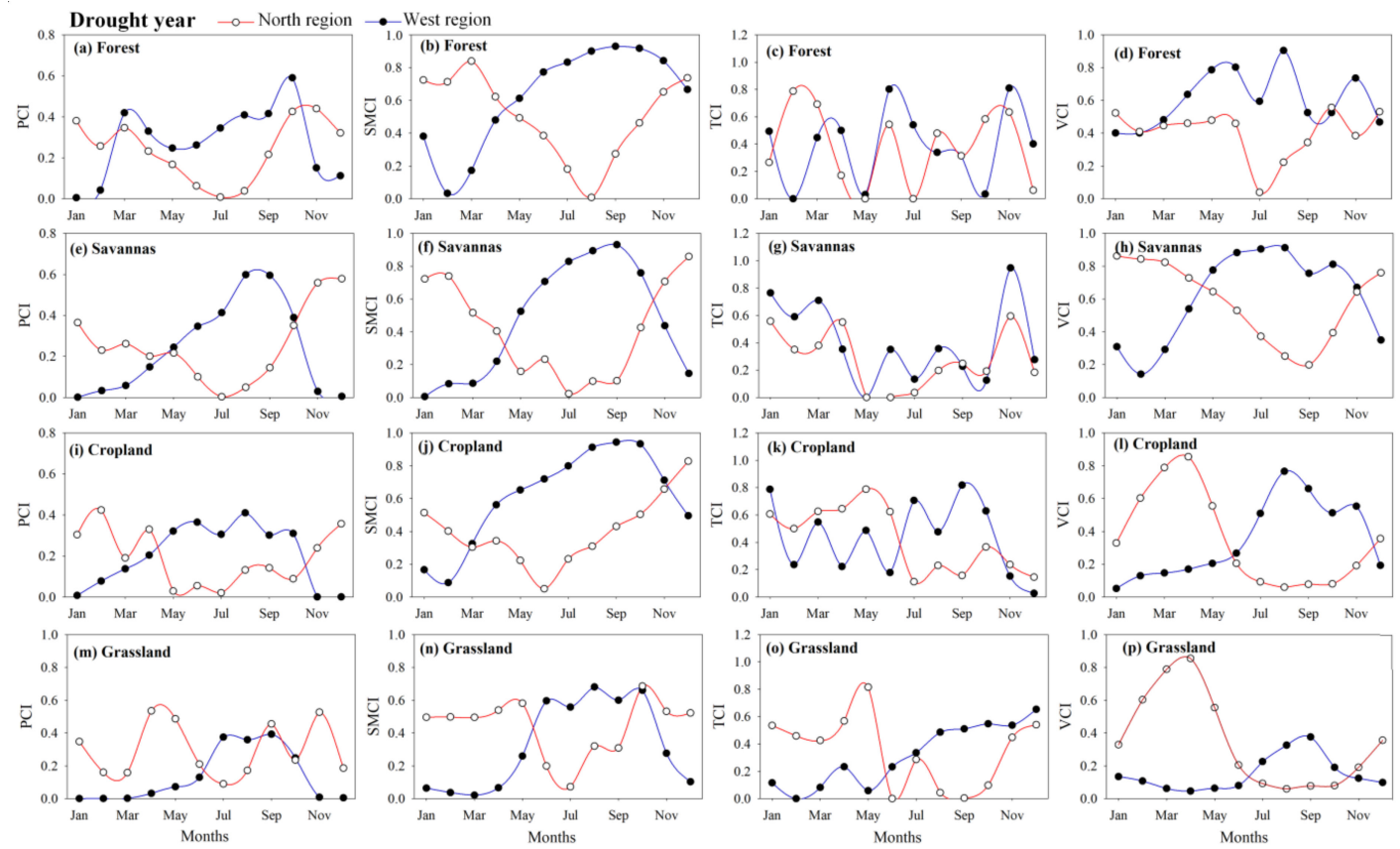

Figure 15. (a-d) Forest, (e-h) savannas, (i-1) Croplands, and (m-p) Grasslands response to drought derived from PCI, SMCI, TCI, and VCI in North and West regions during drought year (2010).

Figure 16 presents the temporal response profiles of the selected LC pixels to PCI, SMCI, TCI, and VCI in (NW) regions of the study area during a normal year. The PCI trend illustrates that, in the West region, Forest, Croplands, and Savannas are under extreme drought conditions from November to March. Grasslands were under extreme drought conditions from September to May. In the North region, the four LC types experienced drought conditions from April to July. The SMCI shows that Forest, Savannas, Croplands, and Grasslands are under severe drought conditions during July in the North region, while in the West region, Forest, Savannas, and Croplands are under moderate drought conditions from December to March, and the Grasslands were under extreme drought conditions from September to May. For TCI, the trend shows that Grasslands have experienced extreme drought conditions during February in the West region, while in North region during the summer season. For Forest, Croplands, and Savannas, it shows a variation between wet and dry spells. The curve of VCI shows no drought conditions occurred for the Forest in both regions. Savannas were under moderate drought conditions from January to March in the West region, and no drought occurred in the North region. Croplands are under Extreme to abnormal drought conditions from June to November in the North region and December to March in the West region. Grasslands are under extreme drought conditions from November to June in the West region and June to July in the North region. 


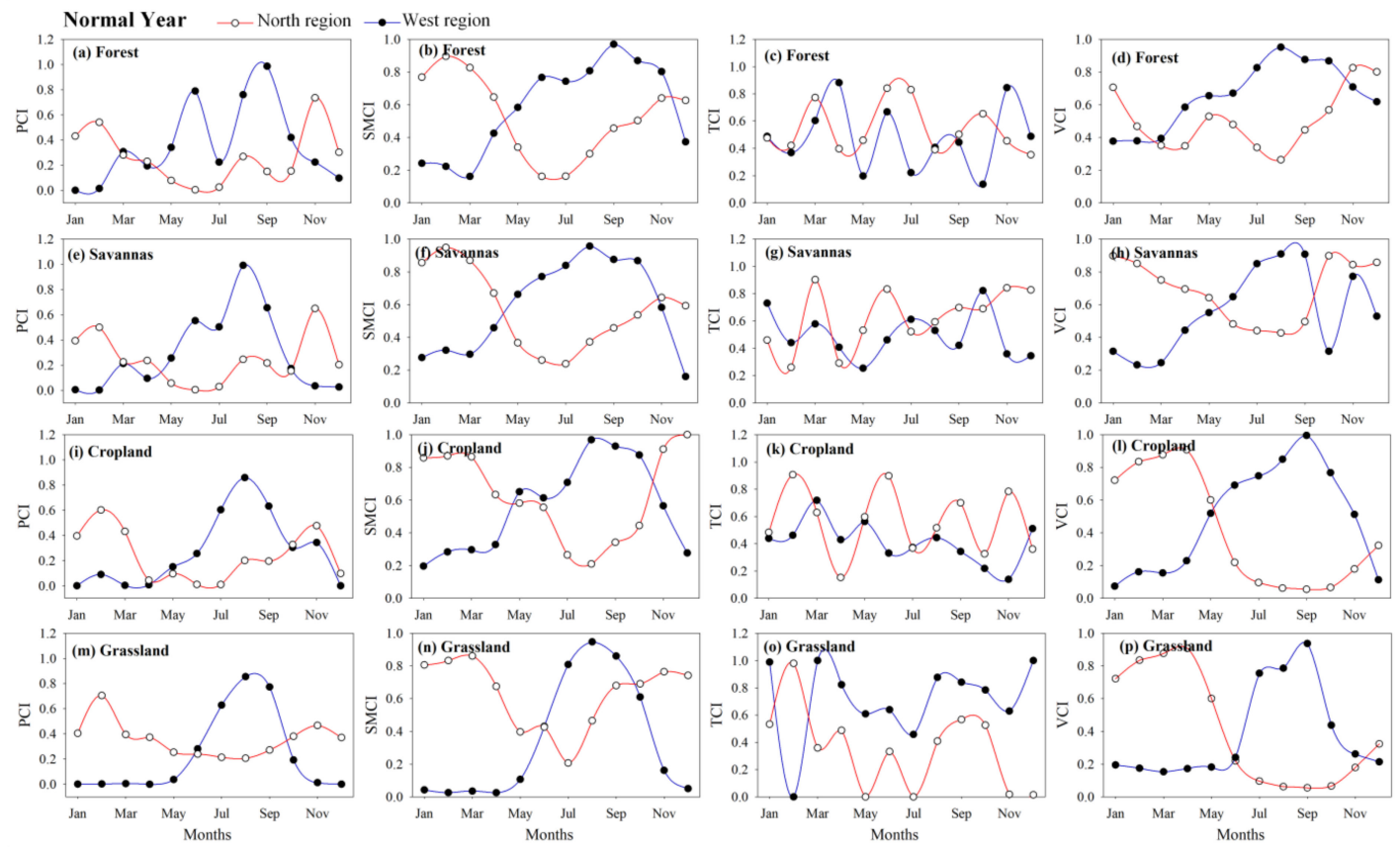

Figure 16. (a-d) Forest, $(\mathbf{e}-\mathbf{h})$ savannas, $(\mathbf{i}-\mathbf{l})$ Croplands, and $(\mathbf{m}-\mathbf{p})$ Grasslands response to drought derived from PCI, SMCI, TCI, and VCI in North and West Africa during normal year.

During the drought year, in the North region, PCI is $<0.4$ for Forest, Croplands, and Grasslands, and $<0.6$ for Savannas; SMCI are $<0.8$ for Forest and Savannas, and $<0.6$ for Croplands and Grasslands; VCI is $<0.6$ for Forest, and $<0.8$ for Savannas, Croplands, and Grasslands. In West region, PCI are $<0.4$ for Croplands and Grasslands, and $<0.6$ for Forest and Savannas; SMCI are $<0.9$ for Forest, Savannas and Croplands, and $<0.6$ for Grasslands; VCI are $>0.4$ for Forest, $<0.4$ for Grasslands, $<0.8$ for Croplands and Savannas. For TCI the four LC are $<0.8$ in (NW) regions (Figure 15). In the normal year, the four drought indices values $\approx 1.0$ during the rainy season. While for PCI values $<0.6$ across Grasslands and Croplands in the west region and Savannas, Grasslands, and Croplands in the North region (Figure 16).

\subsection{Correlation Analysis}

Figure 17 presents the $\mathrm{R}^{2}$ values among the NDVI, SM, LST, and TRMM. There were non-linear relationships among the indices, therefore the "goodness to fit" test was used to find the suitable non-linear model $[64,65]$. The "goodness to fit" test result shows that quadratic and inverse third order are the most suitable non-linear models. Therefore, these two non-linear and one linear model were used to predict the relationships among the indices. A high $\mathrm{R}^{2}$ value was obtained for the quadratic correlation among the SM with NDVI or LST, or TRMM and TRMM with LST, with $\mathrm{R}^{2}$ values of 0.83 , or 0.30 , or 0.73 and 0.56 , respectively. For inverse third order, high $R^{2}$ values $\left(R^{2}=0.34\right.$, and 0.71$)$ obtained a correlation among NDVI with LST and TRMM. Overall, the non-linear model's shows the best fitting. 

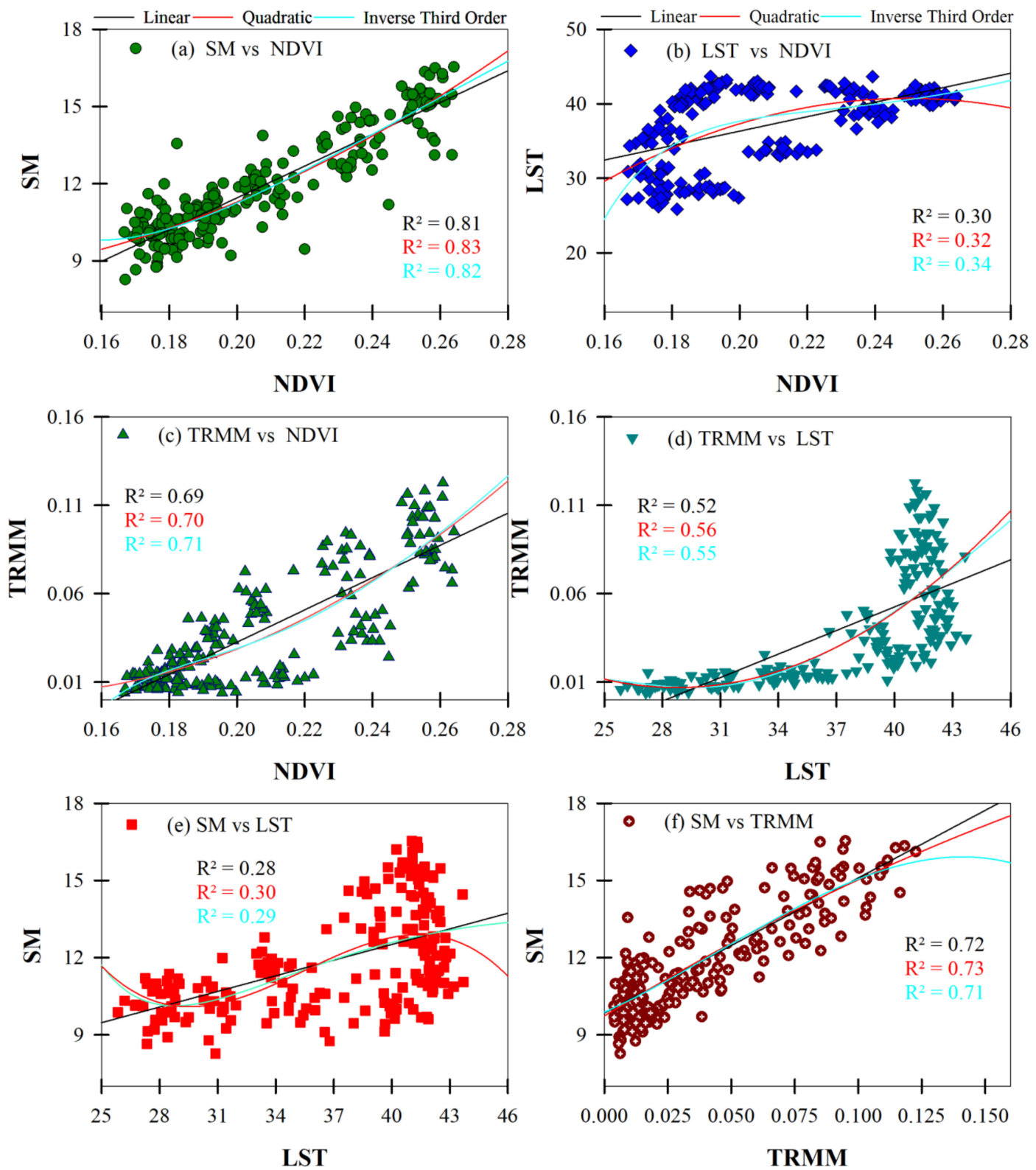

Figure 17. Scatterplot of (a) SM and NDVI, (b) LST and NDVI, (c) TRMM and NDVI, (d) LST and TRMM, (e) LST and SM, (f) SM and TRMM.

\section{Discussion}

The NVSWI was used to predict the drought frequency, and scPDSI was used to monitor the dry and wet spells over the study region from 2002 to 2018. Our result revealed that 2002, 2009, 2010, and 2016 are the dry years, and 2014 and 2015 are normal years. Our findings were partially consistent with Ghoneim et al. [53] they studied the vegetation drought analysis in Tunisia (North Africa), and find that year 2002 is the driest year. Further scPDSI at one-, three-, six-, nine-, and 12-month timescales were used to evaluate the effects of scPDSI application on drought monitoring and focused on differences in a timescale that they reflected. Our results illustrations the consistent finding for these dry and normal years using scPDSI at one-, three-, six-, nine-, and12 months. Zhao et al. [27] and van der Schrier et al. [50] reported that scPDSI is a suitable drought index for short and long-term drought monitoring. Additionally, to better understand the extent of spatial change of drought, we compared the shifting between vegetation and desert cover among the selected dry and normal years. Our result shows that during dry years, the desert turns into a vegetated area, while during 
normal years, the vegetation evolves into a desert area. Foley et al. [59] studied the Regime Shifts in the Sahara and Sahel in Africa. They mentioned that the fluctuating status between desert and vegetation seems to be triggered by a strong interaction between climate and vegetation cover, which might be caused by slow changes in either sea-surface temperatures or land degradation.

To analyze the relationship between climate and vegetation, the correlation performed between VCI, TCI, SMCI, PCI, and scPDSI at different timescale of each LC type (Forest, Savannas, Croplands, and Grasslands) over (NW) regions. Our result revealed that the one-month scPDSI has a higher correlation with PCI compared to the other timescales. That is reasonable because precipitation is a key element in both indices. The highest correlation values were observed for Grasslands among VCI and one-month scPDSI. While the VCI and three-month scPDSI obtained a higher correlation for the Croplands in (NW) regions. For Forest, the higher correlation was between six-month scPDSI and VCI. It is a reasonable Grasslands surface always in water stress (or insufficient moisture) condition. Therefore, short term precipitation (drought) deficit also immediately affects the vegetation conditions. For the Forest and Croplands vegetation, the short term precipitation deficit did not affect the vegetation because NDVI or VCI is sensitive to the amount of chlorophyll in the vegetation foliage [43]. In short term precipitation deficit conduction, it remains green for some time due to sufficient moisture availability for the plant [44]. Therefore, NDVI or VCI does not change immediately. Similar findings observed by Javed et al. [66] correlated the SPI and VCI and found that three-month SPI had a higher correlation with VCI for Croplands, six-month SPI across the Forest land, and one-month SPI at the Grasslands.

Our results exposed that the Croplands and Grasslands were more sensitive to drought in the West region. While in the North region, Savannas, Grasslands, and Croplands were more sensitive to drought risk. These findings were consistent with Ghoneim et al. [53], they reported that Grasslands and Croplands are the most susceptible vegetation types to drought risk. Also, Measho et al. [43] analyzed the spatiotemporal vegetation dynamics to respond to climate variability and drought patterns. They confirmed that sparse vegetation, Grasslands, and Croplands areas were highly vulnerable to drought risk in Africa's semiarid region.

Zribi et al. [14] mentioned that drylands regions are one of the more sensitive regions to climate change, and the increase of temperature, evapotranspiration, and developing human activities will intensify the risk of land degradation. Therefore, it is necessary to understand the correlation analysis between vegetation and climate element [67-72]. The results exposed that NDVI, TRMM, and SM were more suitable for monitoring drought and impact on vegetation over the study area. Gómez-Giráldez et al. [73] assess the correlation between NDVI, TRMM, and SM during the four growing seasons. A higher correlation was found early and the last stage of the dry season between the NDVI and TRMM or SM. Therefore, it will be interesting to study the drought impact on different phenological stages. Our results show that LST had a lower correlation with other indices. Rousta et al. [74] used different indices derived from the MODIS, LST, and TRMM datasets to evaluate the effects of drought on vegetation in Afghanistan. They reported that a lower correlation was found between the LST and TRMM. Ford et al. [75] indicated that the relationship between SM and TRMM showed that the excess amounts of soil moisture in excess soil moisture regions are well consistent with the heavy precipitation areas. Hao et al. [29] mention that the relationship between TRMM and LST is that TRMM can affect SM, which can affect surface temperature by controlling the partitioning between the sensible and latent heat fluxes. Sun et al. [76] mentioned that, in an environment of water scarcity, the magnitude of low correlations between LST, NDVI, and SM are controlled by the soil water accessibility. Hence, areas with the least vegetation are experiencing higher land surface temperatures. The soil temperature affects plant growth indirectly by affecting water and nutrient uptake and root growth. At a constant SM content, a decrease in temperature results in decreased water and nutrient uptake. At low temperatures, transport from the root to the shoot and vice versa is reduced $[77,78]$. Thus, understanding and characterizing vegetation dynamics concerning drought 
patterns is essential to build a base for local drought predictions associated with climate models and downscale multi-model projections.

\section{Conclusions}

In this study, scPDSI, PCI, SMCI, TCI, and VCI were used to monitor the drought and assess the impact of drought on vegetation across North and West Africa from 2002 to 2018. The scPDSI was used to identify the dry and wet spells and then analyze its impact on vegetation at different timescale. The results revealed that drought intensity decreased with increase in the scPDSI timescale. The highest correlation was observed between VCI and one-month scPDSI in Grasslands, in Croplands between VCI and three-month scPDSI, and Forest between VCI and six-month scPDSI. The responses of various LC types to drought indices during the four dry years $(2002,2009,2010$ and 2016) and the two normal years (2014 and 2015) show that Grasslands and Croplands in the West region, and Savannas, Grasslands, and Croplands in the North region are most vulnerable to drought risk. The correlation analysis revealed a higher correlation $\left(\mathrm{R}^{2}>0.70\right)$ between NDVI, TRMM, and SM and enabled a reliable accurate drought prediction. The procedures used in this research have identified the major drought events over NW Africa regions and highlighted which vegetation types sensitive to the drought risk. The findings are crucial for future agricultural planning purposes and can be used as a basis for a drought Decision-Support System to enact appropriate protection measures and mitigate future drought events. Therefore, it is essential to mention that the proposed methodology could be adapted, with appropriate adjustments for other regions.

Author Contributions: Conceptualization, M.H., B.E., and J.Z.; methodology, M.H.; T.J., S.Z., Y.B., and J.Z.; software, M.H.; Q.L., and T.J.; validation, M.H., T.J., S.Z., Y.B., and J.Z.; formal analysis, M.H. and T.J.; investigation, M.H., T.J., S.Z., Y.B., and J.Z.; resources, M.H.; Q.L., and T.J.; data curation, M.H.; Q.L., and T.J.; writing—original draft preparation, M.H.; writing—review and editing, M.H., B.E., T.J., and J.Z.; visualization, M.H., B.E., T.J., and J.Z.; supervision, J.Z.; project administration, J.Z.; funding acquisition, J.Z. All authors have read and agreed to the published version of the manuscript.

Funding: This research was funded by the CAS Strategic Priority Research Program (No. XDA19030402), National Natural Science Foundation of China (No. 42071425), Key Basic Research Project of Shandong Natural Science Foundation of China (No. ZR2017ZB0422), “Taishan Scholar" Project of Shandong Province.

Acknowledgments: We appreciate NASA for providing the MODIS data to do this research (https://ladsweb. modaps.eosdis.nasa.gov). The CAS Strategic Priority Research Program (No. XDA19030402), National Natural Science Foundation of China (No. 42071425), Key Basic Research Project of Shandong Natural Science Foundation of China (No. ZR2017ZB0422), "Taishan Scholar" Project of Shandong Province. We are grateful to the native English speaker for their help in improving the English grammar of this paper.

Conflicts of Interest: The authors declare no conflict of interest.

\section{References}

1. Wilhite, D.A. Drought as a natural hazard: Concepts and denitions. In Drought, A Global Assessment; Wilhite, D.A., Ed.; Routledge: London, UK, 2000; Volume I, pp. 3-18.

2. Igbawua, T.; Zhang, J.; Chang, Q.; Yao, F. Vegetation dynamics in relation with climate over Nigeria from 1982 to 2011. Environ. Earth Sci. 2016, 75, 518-533. [CrossRef]

3. Igbawua, T.; Zhang, J.; Yao, F.; Zhang, D. Assessment of moisture budget over West Africa using MERRA-2's aerological model and satellite data. Clim. Dyn. 2019, 52, 83-106. [CrossRef]

4. Kalisa, W.; Zhang, J.; Igbawua, T.; Ujoh, F.; Ebohon, O.J.; Namugiza, J. Spatio-temporal analysis of drought and return periods over the East African region using Standardized Precipitation Index from 1920 to 2016. Agric. Water Manag. 2020, 237, 106195. [CrossRef]

5. Bayarjargal, Y.; Karnieli, A.; Bayasgalan, M.; Khudulmur, S.; Gandush, C.; Tucker, C.J. A comparative study of NOAA-AVHRR derived drought indices using change vector analysis. Remote Sens. Environ. 2006, 105, 9-22. [CrossRef]

6. Zhang, J.; Xu, Y.; Yao, F.; Wang, P.; Guo, W. Advances in estimation methods of vegetation water content based on optical remote sensing techniques. Sci. China Technol. Sci. 2010, 53, 1159-1167. [CrossRef] 
7. Yang, W. Drought Analysis Under Climate Change by Application of Drought Indices and Copulas. Master's Thesis, Portland State University, Portland, OR, USA, 2010.

8. Du, L.; Tian, Q.; Yu, T.; Meng, Q.; Jancso, T.; Udvardy, P.; Huang, Y. A comprehensive drought monitoring method integrating MODIS and TRMM data. Int. J. Appl. Earth Obs. Geoinf. 2013, 23, 245-253. [CrossRef]

9. Udmale, P.; Ichikawa, Y.; Manandhar, S.; Ishidaira, H.; Kiem, A. Farmers perception of drought impacts, local adaptation and administrative mitigation measures in Maharashtra State, India. Int. J. Disast. Risk Sc. 2014, 10, 250-269. [CrossRef]

10. IPCC. Summary for Policymakers. In Climate Change 2013: The Physical Science Basis. Contribution of Working Group I to the Fifth Assessment Report of the Intergovernmental Panel on Climate Change; Cambridge University Press: Cambridge, UK, 2013; Available online: https://www.ipcc.ch/site/assets/ uploads/2018/02/WG1AR5_SPM_FINAL.pdf (accessed on 1 November 2020).

11. Maximilian, S.; Landmann, T.; Cornish, N.; Wetzel, K.; Siebert, S.; Franke, J. A Spatially Transferable Drought Hazard and Drought Risk Modeling Approach Based on Remote Sensing Data. Remote Sens. 2020, 12, 237. [CrossRef]

12. Masih, I.; Maskey, S.; Mussá, F.E.F.; Trambauer, P. A review of droughts on the African continent: A geospatial and long-term perspective. Hydrol. Earth Syst. Sci. 2014, 18, 3635-3649. [CrossRef]

13. Amri, R.; Zribi, M.; Duchemin, B.; Lili-Chabaane, Z.; Gruhier, C.; Chebouni, A. Analysis of vegetation behavior in a semi-arid region, using SPOT-VEGETATION NDVI data. Remote Sens. 2011, 3, 2568-2590. [CrossRef]

14. Zribi, M.; Dridi, G.; Amri, R.; Lili-Chabaane, Z. Analysis of the Effects of Drought on Vegetation Cover in a Mediterranean Region through the Use of SPOT-VGT and TERRA-MODIS Long Time Series. Remote Sens. 2016, 8, 992. [CrossRef]

15. Blakeley, S.L.; Sweeney, S.; Husak, G.; Harrison, L.; Funk, C.; Peterson, P.; Osgood, D.E. Identifying Precipitation and Reference Evapotranspiration Trends in West Africa to Support Drought Insurance. Remote Sens. 2020, 12, 2432. [CrossRef]

16. Nicholson, S.E. The West African Sahel: A review of recent studies on the rainfall regime and its inter-annual variability. ISRN Meteorol. 2013, 453521. [CrossRef]

17. Touchan, R.; Anchukaitis, K.J.; Meko, D.M.; Sabir, M.; Attalah, S.; Aloui, A. Spatiotemporal drought variability in northwestern Africa over the last nine centuries. Clim. Dyn. 2011, 37, 237-252. [CrossRef]

18. Shiferaw, B.; Tesfaye, K.; Kassie, M.; Abate, T.; Prasanna, B.M.; Menkir, A. Managing vulnerability to drought and enhancing livelihood resilience in sub-Saharan Africa: Technological, institutional and policy options. Weather Clim. Extrem. 2014, 3, 67-79. [CrossRef]

19. Bhavani, R.; Vordzorgbe, S.; Owor, M.; Bousquet, F. Report on the Disaster Risk Reduction in the Sub-Saharan Africa Region. The World Bank. 2008. Available online: https://www.unisdr.org/files/2229_ DRRinSubSaharanAfricaRegion.pdf (accessed on 1 November 2020).

20. Brown, C.; Meeks, R.; Hunu, K. Hydroclimate risk to economic growth in sub-Saharan Africa. Clim. Chang. 2011, 106, 621-647. [CrossRef]

21. Hellmuth, M.E.; Moorhead, A.; Thomas, M.C.; Williams, J. Climate Risk Management in Africa: Learning from Practice; International Research Institute for Climate and Society (IRI), Columbia University: New York, NY, USA, 2007; Available online: https://iri.columbia.edu/wp-content/uploads/2013/07/Climate-and-Society-No1_en.pdf (accessed on 2 November 2020).

22. Kim, J.S.; Jain, S.; Lee, J.H.; Chen, H.; Park, S.Y. Quantitative vulnerability assessment of water quality to extreme drought in a changing climate. Ecol. Indic. 2019, 103, 688-697. [CrossRef]

23. Palmer, W.C. Meteorological Drought; Research Paper No. 45; U.S. Department of Commerce Weather Bureau: Washington, DC, USA, 1965. Available online: https://www.ncdc.noaa.gov/temp-and-precip/drought/docs/ palmer.pdf (accessed on 2 November 2020).

24. McKee, T.B.; Doesken, N.J.; Kleist, J. The relationship of drought frequency and duration to time scales. In Proceedings of the 8th Conference on Applied Climatology, Anaheim, CA, USA, 17-22 January 1993; pp. 179-184.

25. Beguería, S.; López-Moreno, J.I. A multiscalar drought index sensitive to global warming: The standardized precipitation evapotranspiration index. J. Clim. 2010, 23, 1696-1718. [CrossRef] 
26. Thornthwaite, C.W.; Mather, J.A.; Thornthwaite, W. The Water Balance: Publications in Climatology, Laboratory of Climatology; Climatol: Centerton, NJ, USA, 1955; Volume 8. Available online: https://books.google.fr/books/ about/The_Water_Balance.html?id=DTdtcgAACAAJ\&redir_esc=y (accessed on 3 November 2020).

27. Zhao, H.; Gao, G.; An, W.; Zou, X.; Li, H.; Hou, M. Timescale differences between SC-PDSI and SPEI for drought monitoring in China. Phys. Chem. Earth 2015, 102, 48-58. [CrossRef]

28. Wells, N.; Goddard, S.; Hayes, M.J. A Self-Calibrating Palmer Drought Severity Index. J. Clim. 2004, 17, 2335-2351. [CrossRef]

29. Hao, C.; Zhang, J.; Yao, F. Combination of multi-sensor remote sensing data for drought monitoring over Southwest China. Int. J. Appl. Earth Obs. Geoinf. 2015, 35, 270-283. [CrossRef]

30. Xu, P.; Zhou, T.; Zhao, X.; Luo, H.; Gao, S.; Li, Z.; Cao, L. Diverse responses of different structured forest to drought in Southwest China through remotely sensed data. Int. J. Appl. Earth Obs. 2018, 69, 217-225. [CrossRef]

31. Zhang, J.; Zhou, Z.; Yao, F.; Yang, L.; Hao, C. Validating the Modified Perpendicular Drought Index in North China Region Using in Situ Soil Moisture Measurement. IEEE T Geosci. Remote. 2015, 12, 542-546. [CrossRef]

32. Dianmin, C.; Shuhe, Z.; Cheng, C.; Zheng, D. Characterization of droughts during 2001-2014 based on remote sensing: A case study of Northeast China. Ecol. Inform. 2017, 39, 56-67. [CrossRef]

33. Ali, S.; Henchiri, M.; Yao, F.; Zhang, J. Analysis of vegetation dynamics, drought in relation with climate over South Asia from 1990 to 2011. Environ. Sci. Pollut. Res. 2019, 26, 11470-11481. [CrossRef]

34. Li, X.; Sha, J.; Wang, Z. Comparison of drought indices in the analysis of spatial and temporal changes of climatic drought events in a basin. Environ. Sci. Pollut. Res. 2019, 26, 10695-10707. [CrossRef]

35. Liu, W.T.; Kogan, F.N. Monitoring regional drought using the Vegetation Condition Index. Int. J. Remote Sens. 1996, 17, 2761-2782. [CrossRef]

36. Faridatul, M.I.; Ahmed, B. Assessing Agricultural Vulnerability to Drought in a Heterogeneous Environment: A Remote Sensing-Based Approach. Remote Sens. 2020, 12, 3363. [CrossRef]

37. Qu, C.; Hao, X.; Qu, J.J. Monitoring Extreme Agricultural Drought over the Horn of Africa (HOA) Using Remote Sensing Measurements. Remote Sens. 2019, 11, 902. [CrossRef]

38. Kogan, F.N. Droughts of the Late 1980s in the United States as Derived from NOAA Polar Orbiting Satellite Data. Bull. Amer. Meteor. Soc. 1995, 76, 655-668. [CrossRef]

39. Ahmadalipour, A.; Moradkhani, H. Multi-dimensional assessment of drought vulnerability in Africa: 1960-2100. Sci. Total Environ. 2018, 644, 520-535. [CrossRef] [PubMed]

40. Ahmadalipour, A.; Moradkhani, H. Escalating heat-stress mortality risk due to global warming in the Middle East and North Africa (MENA). Environ. Int. 2018, 117, 215-225. [CrossRef] [PubMed]

41. Buma, W.G.; Lee, S.-I. Multispectral Image-Based Estimation of Drought Patterns and Intensity around Lake Chad, Africa. Remote Sens. 2019, 11, 2534. [CrossRef]

42. Winkler, K.; Gessner, U.; Hochschild, V. Identifying Droughts Affecting Agriculture in Africa Based on Remote Sensing Time Series between 2000-2016: Rainfall Anomalies and Vegetation Condition in the Context of ENSO. Remote Sens. 2017, 9, 831. [CrossRef]

43. Measho, S.; Chen, B.; Trisurat, Y.; Pellikka, P.; Guo, L.; Arunyawat, S.; Tuankrua, V.; Ogbazghi, W.; Yemane, T. Spatio-Temporal Analysis of Vegetation Dynamics as a Response to Climate Variability and Drought Patterns in the Semiarid Region, Eritrea. Remote Sens. 2019, 11, 724. [CrossRef]

44. Zhao, H.; Ma, Y. Evaluating the Drought-Monitoring Utility of Four Satellite-Based Quantitative Precipitation Estimation Products at Global Scale. Remote Sens. 2019, 11, 2010. [CrossRef]

45. AghaKouchak, A.; Farahmand, A.; Melton, F.S.; Teixeira, J.; Anderson, M.C.; Wardlow, B.D.; Hain, C.R. Remote sensing of drought: Progress, challenges and opportunities. Rev. Geophys. 2015, 53, 452-480. [CrossRef]

46. Bobadoye, A.O. Assessing Vulnerability to Climate Change and the Impact of Drought on Vegetation Productivity in West Africa. Ph.D. Thesis, University of Nairobi, Nairobi, Kenya, 2018. [CrossRef]

47. NourEldeen, N.; Mao, K.; Yuan, Z.; Shen, X.; Xu, T.; Qin, Z. Analysis of the Spatiotemporal Change in Land Surface Temperature for a Long-Term Sequence in Africa (2003-2017). Remote Sens. 2020, 12, 488. [CrossRef]

48. Henchiri, M.; Shahzad, A.; Essifi, B.; Kalisa, W.; Zhang, S.; Bai, Y. Monitoring land cover change detection with NOAA-AVHRR and MODIS remotely sensed data in the North and West of Africa from 1982 to 2015. Environ. Sci. Pollut. Res. 2019, 6, 5873-5889. [CrossRef] 
49. Zhao, M.; Velicogna, G.A.; Kimball, J.S. A global gridded dataset of GRACE drought severity index for 2002-2014: Comparison with PDSI and SPEI and a case study of the Australia Millennium Drought. J. Hydrometeor. 2017, 18, 2117-2129. [CrossRef]

50. Van der Schrier, G.; Barichivich, J.; Briffa, K.R.; Jones, P.D. A scPDSI-based global data set of dry and wet spells for 1901-2009. J. Geophys. Res. Atmos. 2013, 118, 4025-4048. [CrossRef]

51. Eklundh, L.; Jönsson, P. TIMESAT 3.2 with Parallel Processing Software Manual; Lund University and Malmo University: Lund, Sweden, 2015; Available online: http://web.nateko.lu.se/timesat/docs/TIMESAT32 software_manual.pdf (accessed on 12 August 2020).

52. Ali, S.; Tong, D.; Xu, Z.T.; Henchiri, M.; Wilson, K.; Siqi, S.; Zhang, J. Characterization of drought monitoring events through MODIS-and TRMM-based DSI and TVDI over South Asia during 2001-2017. Environ. Sci. Pollut. Res. Int. 2019, 32, 33568-33581. [CrossRef] [PubMed]

53. Ghoneim, E.; Dorofeeva, A.; Benedetti, M.; Gamble, D.; Leonard, L.; AbuBakr, M. Vegetation Drought Analysis in Tunisia: A Geospatial Investigation. J. Atmos. Sci. 2017, 1, 2. [CrossRef]

54. Hazaymeh, K.; Hassan, Q. Remote sensing of agricultural drought monitoring: A state of art review. AIMS Environ. Sci. 2016, 3, 604-630. [CrossRef]

55. Peters, A.J.; Walter-Shea, E.A.; Ji, L.; Vina, A.; Hayes, M.; Svoboda, M.D. Drought monitoring with NDVI-based standardized vegetation index. Photogramm. Eng. Remote Sens. 2002, 68, 71-75.

56. Liu, Q.; Zhang, S.; Zhang, H.; Bai, Y.; Zhang, J. Monitoring drought using composite drought indices based on remote sensing. Sci. Total Environ. 2020, 711, 13585. [CrossRef] [PubMed]

57. Abbas, S.; Nichol, J.E.; Qamer, F.M.; Xu, J. Characterization of drought development through remote sensing: A case study in central Yunnan, China. Remote Sens. 2014, 6, 4998-5018. [CrossRef]

58. Ren, S.; Qin, Q.; Ren, H.; Sui, J.; Zhang, Y. Heat and Drought Stress Advanced Global Wheat Harvest Timing from 1981-2014. Remote Sens. 2019, 11, 971. [CrossRef]

59. Foley, A.; Coe, M.T.; Scheffer, M.; Wang, G. Regime Shifts in the Sahara and Sahel: Interactions between Ecological and Climatic Systems in Northern Africa. Ecosystems 2003, 6, 524-539. [CrossRef]

60. Nanzad, L.; Zhang, J.; Tuvdendorj, B.; Nabil, M.; Zhang, S.; Bai, Y. NDVI anomaly for drought monitoring and its correlation with climate factors over Mongolia from 2000 to 2016. J. Arid Environ. 2019, 164, 69-77. [CrossRef]

61. Drori, R.; Dan, H.; Sprintsin, M.; Sheffer, E. Precipitation-Sensitive Dynamic Threshold: A New and Simple Method to Detect and Monitor Forest and Woody Vegetation Cover in Sub-Humid to Arid Areas. Remote Sens. 2020, 12, 1231. [CrossRef]

62. Zhang, A.; Jia, G. Monitoring meteorological drought in semiarid regions using multi-sensor microwave remote sensing data. Remote Sens. Environ. 2013, 134, 12-23. [CrossRef]

63. Zhang, L.; Jiao, W.; Zhang, H.; Huang, C.; Tong, Q. Studying drought phenomena in the Continental United States in 2011 and 2012 using various drought indices. Remote Sens. Environ. 2017, 190, 96-106. [CrossRef]

64. Onyutha, C. On Rigorous Drought Assessment Using Daily Time Scale: Non-Stationary Frequency Analyses, Revisited Concepts, and a New Method to Yield Non-Parametric Indices. Hydrology 2017, 4, 48. [CrossRef]

65. Kalisa, W.; Igbawua, T.; Henchiri, M.; Ali, S.; Zhang, S.; Bai, Y.; Zhang, J. Assessment of climate impact on vegetation dynamics over East Africa from 1982 to 2015. Sci. Rep. 2019, 9, 16865. [CrossRef]

66. Javed, T.; Yao, N.; Chen, X.; Suon, S.; Li, Y. Drought evolution indicated by meteorological and remote-sensing drought indices under different land cover types in China. Environ. Sci. Pollut. Res. 2020, 27, 4258-4274. [CrossRef]

67. Vicenteserrano, S.M.; Beguería, S.; Lópezmoreno, J.I.; Angulo, M.; Kenawy, A.E. A new global 0.58 gridded dataset (1901-2006) of a multiscalar drought index: Comparison with current drought index datasets based on the Palmer drought severity index. J. Hydrometeor. 2010, 11, 1033-1043. [CrossRef]

68. Waha, K.; Krummenauer, L.; Adams, S.; Aich, V.; Baarsch, F.; Coumou, D.; Fader, M.; Hoff, H.; Jobbins, G.; Marcus, R. Climate change impacts in the Middle East and Northern Africa (MENA) region and their implications for vulnerable population groups. Reg. Environ. Change 2017, 17, 1623-1638. [CrossRef]

69. Abera, W.; Tamene, L.; Abegaz, A.; Solomon, D. Understanding climate and land surface changes impact on water resources using Budyko framework and remote sensing data in Ethiopia. J. Arid Environ. 2019, 167, 56-64. [CrossRef]

70. Huang, J.P.; Yu, H.P.; Guan, X.D.; Wang, G.Y.; Guo, R.X. Accelerated dryland expansion under climate change. Nat. Clim. Chang. 2016, 6, 166-171. [CrossRef] 
71. Dai, A.; Zhao, T.; Chen, J. Climate Change and Drought: A Precipitation and Evaporation Perspective. Curr. Clim. Chang. Rep. 2018, 4, 301-312. [CrossRef]

72. Lehner, F.; Coats, S.; Stocker, T.F.; Pendergrass, A.G.; Sanderson, M.; Raible, C.C.; Smerdon, J.E. Projected drought risk in $1.5^{\circ} \mathrm{C}$ and $2{ }^{\circ} \mathrm{C}$ warmer climates. Geophys. Res. Lett. 2017, 44, 7419-7428. [CrossRef]

73. Gómez-Giráldez Pedro, J.; Pérez-Palazón María, J.; Polo María, J.; González-Dugo María, P. Monitoring Grass Phenology and Hydrological Dynamics of an Oak-Grass Savanna Ecosystem Using Sentinel-2 and Terrestrial Photography. Remote Sens. 2020, 12, 600. [CrossRef]

74. Rousta, I.; Olafsson, H.; Moniruzzaman, M.; Zhang, H.; Liou, Y.-A.; Mushore, T.D.; Gupta, A. Impacts of Drought on Vegetation Assessed by Vegetation Indices and Meteorological Factors in Afghanistan. Remote Sens. 2020, 12, 2433. [CrossRef]

75. Ford, T.; Quiring, S.; Thakur, B.; Jogineedi, R.; Houston, A.; Yuan, S.; Kalra, A.; Lock, N. Evaluating Soil Moisture-Precipitation Interactions Using Remote Sensing: A Sensitivity Analysis. J. Hydrometeorol. 2018, 19, 1237-1253. [CrossRef]

76. Sun, D.; Kafatos, M. Note on the NDVI-LST relationship and the use of temperature-related drought indices over North America. J. Geophys. Res. Lett. 2007, 34, L24406. [CrossRef]

77. Swain, S.; Wardlow, B.D.; Narumalani, S.; Tadesse, T.; Callahan, K. Assessment of Vegetation Response to Drought in Nebraska Using Terra MODIS Land Surface Temperature and Normalized Difference Vegetation Index. GISci. Remote Sens. 2011, 48, 432-455. [CrossRef]

78. Dracup, J.A.; Lee, K.S.; Paulson, E.G. on the definition of droughts. Water Resour. Res. 1980, 16, $289-296$. [CrossRef]

Publisher's Note: MDPI stays neutral with regard to jurisdictional claims in published maps and institutional affiliations.

(C) 2020 by the authors. Licensee MDPI, Basel, Switzerland. This article is an open access article distributed under the terms and conditions of the Creative Commons Attribution (CC BY) license (http://creativecommons.org/licenses/by/4.0/). 